\title{
Dynamic brightness induction in V1: Analyzing simulated and empirically acquired fMRI data in a "common brain space" framework
}

\author{
Citation for published version (APA):
}

Peters, J. C., Jans, B., van de Ven, V. G., de Weerd, P., \& Goebel, R. (2010). Dynamic brightness induction in V1: Analyzing simulated and empirically acquired fMRI data in a "common brain space" framework. Neuroimage, 52(3), 973-984. https://doi.org/10.1016/j.neuroimage.2010.03.070

Document status and date:

Published: 01/09/2010

DOI:

10.1016/j.neuroimage.2010.03.070

Document Version:

Publisher's PDF, also known as Version of record

\section{Document license:}

Taverne

Please check the document version of this publication:

- A submitted manuscript is the version of the article upon submission and before peer-review. There can be important differences between the submitted version and the official published version of record. People interested in the research are advised to contact the author for the final version of the publication, or visit the DOI to the publisher's website.

- The final author version and the galley proof are versions of the publication after peer review.

- The final published version features the final layout of the paper including the volume, issue and page numbers.

Link to publication

\footnotetext{
General rights rights.

- You may freely distribute the URL identifying the publication in the public portal. please follow below link for the End User Agreement:

www.umlib.nl/taverne-license

Take down policy

If you believe that this document breaches copyright please contact us at:

repository@maastrichtuniversity.nl

providing details and we will investigate your claim.
}

Copyright and moral rights for the publications made accessible in the public portal are retained by the authors and/or other copyright owners and it is a condition of accessing publications that users recognise and abide by the legal requirements associated with these

- Users may download and print one copy of any publication from the public portal for the purpose of private study or research.

- You may not further distribute the material or use it for any profit-making activity or commercial gain

If the publication is distributed under the terms of Article 25fa of the Dutch Copyright Act, indicated by the "Taverne" license above, 


\title{
Dynamic brightness induction in V1: Analyzing simulated and empirically acquired fMRI data in a "common brain space" framework
}

\author{
Judith C. Peters ${ }^{\mathrm{a}, \mathrm{b}, \mathrm{c}, *}$, Bert Jans ${ }^{\mathrm{b}, \mathrm{c}}$, Vincent van de Ven ${ }^{\mathrm{b}, \mathrm{c}}$, Peter De Weerd ${ }^{\mathrm{b}, \mathrm{c}, \mathrm{d}}$, Rainer Goebel ${ }^{\mathrm{a}, \mathrm{b}, \mathrm{c}}$ \\ a Department of Neuroimaging and Neuromodeling, Netherlands Institute for Neuroscience, an institute of the Royal Netherlands Academy of Arts and Sciences (KNAW), \\ Amsterdam, The Netherlands \\ ${ }^{\mathrm{b}}$ Department of Cognitive Neuroscience, Faculty of Psychology and Neuroscience, Maastricht University, Maastricht, The Netherlands \\ ${ }^{\mathrm{c}}$ Maastricht Brain Imaging Center (M-BIC), Maastricht University, The Netherlands \\ ${ }^{\mathrm{d}}$ Research Fellow of the Donders Institute for Brain, Cognition and Behaviour, Radboud University, NL
}

\section{A R T I C L E I N F O}

\section{Article history:}

Received 25 September 2009

Revised 6 March 2010

Accepted 24 March 2010

Available online 31 March 2010

\section{Keywords:}

Brightness illusion

Large-scale neuromodeling, neuroimaging

Surface perception

\begin{abstract}
A B S T R A C T
Computational neuromodeling may help to further our understanding of how empirical neuroimaging findings are generated by underlying neural mechanisms. Here, we used a simple computational model that simulates early visual processing of brightness changes in a dynamic, illusory display. The model accurately predicted illusory brightness changes in a grey area of constant luminance induced by (and in anti-phase to) luminance changes in its surroundings. Moreover, we were able to directly compare these predictions with recently observed fMRI results on the same brightness illusion by projecting predicted activity from our model onto empirically investigated brain regions. This new approach in which generated network activity and measured neuroimaging data are interfaced in a common representational "brain space" can contribute to the integration of computational and experimental neuroscience.
\end{abstract}

(c) 2010 Elsevier Inc. All rights reserved.

\section{Introduction}

How surface perception is achieved is not well understood, and a lot of empirical and computational modeling work is devoted to tackle questions on its underlying neuronal mechanisms. The present paper focuses on the perception of surface brightness, and its aims are twofold. First, we aim to build a simple model that generates neuronal activity that correlates with the perception of surface brightness. The model generates specific predictions in the form of a dynamically changing topographic map of activity that captures specific aspects of surface brightness perception. Second, we aim to integrate empirical and computational research by representing empirical and modeled data in a common space. The approach we propose is to project the predicted activity in a modeled area onto corresponding cortical regions where empirical data will be collected, to achieve direct and quantitative hypothesis testing. This requires large-scale neural network modeling combined with a strategy to link modeled units (cortical columns) with specific neuroimaging units (voxels, vertices) in the empirically obtained brain model. To achieve this, modeled and empirical units are connected in a common anatomical space. Here, we show the feasibility of that approach.

\footnotetext{
* Corresponding author. Department of Neuroimaging and Neuromodeling, Netherlands Institute for Neuroscience (KNAW), Meibergdreef 47, 1105 BA Amsterdam, The Netherlands. Fax: + 31206966121.

E-mail address: j.peters@nin.knaw.nl (J.C. Peters).
}

To demonstrate our modeling approach, we will focus on the paradigm of brightness induction, in which an intermediate luminance patch on a bright background appears darker than on a dark background (White, 1979). This illusion is maximized in a dynamic display developed by De Valois et al. (1986), in which a grey area of constant luminance is flanked by areas whose luminance varies sinusoidally between black and white. We refer to the grey area of constant luminance as the "probing region" as we use it to probe mechanisms of surface perception and refer to the areas whose luminance is modulated as the "inducers" (see Fig. 3). The brightness percept in the probing region varies in anti-phase to physical luminance changes of the inducers (see also Fig. 6A). The neuronal mechanisms that cause these illusory brightness changes are not well known. The most convincing evidence comes from neurophysiological recordings in the cat (Rossi and Paradiso, 1999; Rossi et al., 1996), which showed that in about $10 \%$ of area 17 neurons with their receptive fields (RFs) placed within the probing region, activity was modulated in anti-phase to inducer luminance (i.e., activity correlated to perceived brightness changes). Two human studies using functional magnetic resonance imaging (fMRI) have reported data that appear in agreement with the neurophysiological data (Pereverzeva and Murray, 2008; van de Ven et al., in preparation), whereas a third fMRI study (Cornelissen et al., 2006) did not observe a brightness induction correlate in early visual cortex.

The model we propose contains three main parts (Fig. 1). It consists of an input layer which (in essence captures physical luminance values in the image and) gives input to a layer where 


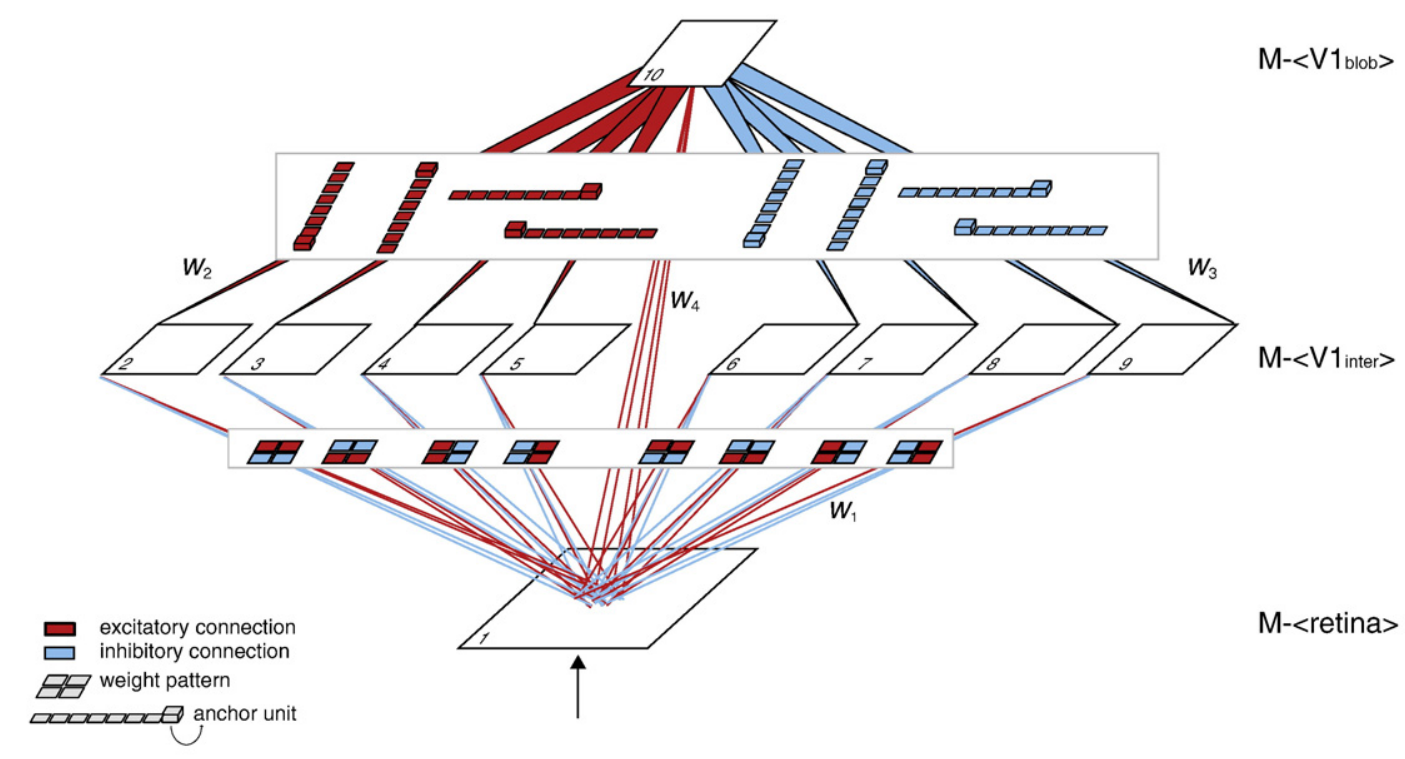

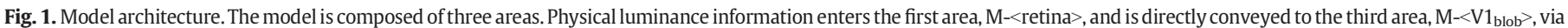

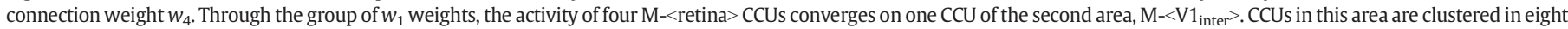

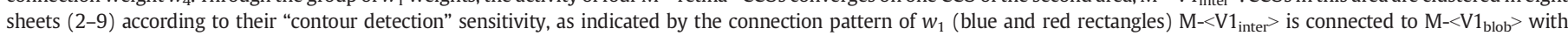

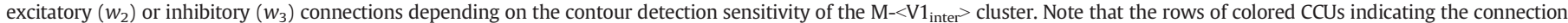

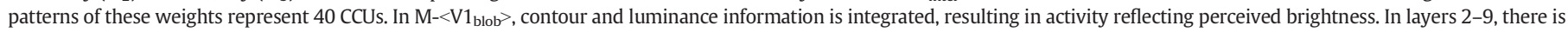

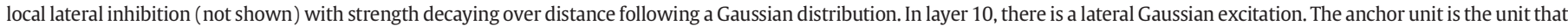
has the same position in the layer as the unit from which it gets input. See Fig. 3 for further details.

contours are extracted from this input and to another layer where measurements across surfaces are modulated by information spreading from contours. In broad terms, this approach is similar to the models of Grossberg and coworkers (Grossberg, 1987a,b, 2003; Grossberg and Todorovic, 1988; Grossberg and Raizada, 2000; Raizada and Grossberg, 2001; see also Gerrits et al., 1966; Gerrits and Vendrik, 1970 ) in which an interaction between contour representations (in the boundary contour system or BCS) and spreading of surface features (in the feature contour system or FCS) leads to the experience of 'visible' surfaces (e.g., Grimson, 1982). The idea that there are separate but interacting streams of visual processing related to the processing of boundaries and the processing of surfaces is supported by anatomical and neurophysiological evidence (see Discussion). For example, V1 blob regions contain neurons that are often well stimulated by homogenous surfaces that extend beyond their RFs, while V1 interblob regions contain neurons that are preferentially stimulated by oriented contrasts (e.g., contours and edges). Without claiming that our model captures the complexity of early visual processing, we will refer to the input layer as the Model retina $(\mathrm{M}-<$ retina $>)$ and the two other layers as the Model V1 blobs $\left(\mathrm{M}-<\mathrm{V} 1_{b_{b l o b}}>\right)$ and Model V1 interblobs $\left(\mathrm{M}-<\mathrm{V} 1_{\text {inter }}>\right)$. Processing in our model thus occurs in two stages: in the first stage of processing, contour information is extracted from local discontinuities in visual input (in $\mathrm{M}-<\mathrm{V} 1_{\text {inter }}>$ ); in the second stage, in $\mathrm{M}-<\mathrm{V} 1_{\mathrm{blob}}>$, contour-related activity from $\mathrm{M}-<\mathrm{V} 1_{\text {inter }}>$ is integrated with $\mathrm{M}-<$ retina $>$ activity reflecting surface-related input. More specifically, contours are used as seeding points from which modulatory activity spreads, affecting the luminance representation in line with the percept. Specific aspects of the present modeling approach that differ from earlier modeling efforts, and their physiological interpretation will be treated in the Discussion.

In parallel with the development of the computational model, we recently acquired fMRI data in an experiment in which induced brightness perception was correlated with activity in early visual areas (van de Ven et al., in preparation). We used a stimulus design adapted from neurophysiological studies (Rossi and Paradiso, 1999; Rossi et al., 1996), in which the brightness perception in a probing region of constant luminance is modulated by surrounding inducer regions that dynamically vary in luminance. In the illusion condition, participants reported a strong brightness illusion in a grey probing region, which was in anti-phase with luminance modulations in the inducers. Participants did not report this illusion in the control condition in which the probe was black instead of grey. This induced brightness percept correlated with activity in retinotopically mapped clusters in striate and extrastriate visual cortex. That is, activity in the probing region changed in anti-phase to physical luminance modulations in inducers in the illusion condition, whereas no activity was observed when the probe surface was black. We investigated the extent to which our simple model predictions captured aspects of cortical activity in response to induced surface brightness.

To relate the output of our model directly to acquired fMRI data, we followed the "common brain space" (CBS) framework (Goebel and Horwitz, in preparation; Goebel and De Weerd, 2009). In this new framework, the processing units of a neural network model are connected to points (vertices) of brain models (cortex meshes) implementing specific spatial hypotheses. As a result, a running network simulation creates time course data directly on a linked brain model allowing to relate predicted and measured topographic neuroimaging data in a highly specific manner, i.e., by using the same data analysis tools (e.g., general linear model or multivoxel pattern analyses).

\section{Methods}

\section{Brightness illusion and brightness control design}

We presented a comparable stimulus design to the neural model and to human subjects (van de Ven et al., in preparation). In the fMRI experiment, the stimulus (see example in lower left of Fig. 3) consisted of an annulus of constant luminance ( $6^{\circ}$ width; probing region) interspersed between a central disk ( $3^{\circ}$ width) and a peripheral annulus ( $6^{\circ}$ width; the inducers). The inducers of the stimulus changed luminance quasi-sinusoidally in $2 \mathrm{~s}$ ( range $=1.1$ $\left.164 \mathrm{~cd} / \mathrm{m}^{2}\right)$, whereas the probe region had a fixed grey $\left(7.9 \mathrm{~cd} / \mathrm{m}^{2}\right.$; induction condition) luminance. After each "up" (inducer change 
from black to white) and "down" (inducer change from white to black) event, the inducers stayed at maximal and minimal luminance respectively, for $5 \mathrm{~s}$. The control condition was identical to the brightness induction condition, except that the probe region was black $\left(1.1 \mathrm{~cd} / \mathrm{m}^{2}\right)$ instead of grey.

Experimental design was similar for the simulation experiments, except that the stimulus covered the entire "visual field," and luminance of the inducers changed quasi-sinusoidally from 0.00 to 1.00 input with probe region luminance fixed on 0.50 (induction condition) or 0.00 (control condition).

\section{Large-scale neural network model}

Our large-scale neural network model (Fig. 1) is composed of three retinotopically organized, square layers representing the retina $(\mathrm{M}-<$ retina $>)$, and the blob $\left(\mathrm{M}-<\mathrm{V} 1_{\mathrm{blob}}>\right)$ and interblob $\left(\mathrm{M}-<\mathrm{V} 1_{\text {inter }}>\right)$ areas in V1. In the employed CBS framework, individual processing units are not representing single neurons but are conceptualized as "cortical column units" (CCUs). We believe this is the appropriate level of modeling, as measuring at the level of cortical columns-the building blocks of the visual system (Hubel and Wiesel, 1959, 1962)is becoming in reach when employing state-of-the-art ultra highfield, fMRI measurements (Yacoub et al., 2008). The CCU's dynamics are defined by the subsequent equations (Goebel, 1993):

$$
\begin{aligned}
& \operatorname{net}_{i}(t)=\sum_{j=1}^{n} w_{i j} a_{j} \\
& a_{i}(t)=(1-\tau) a_{i}(t-1)+\tau \sigma\left(\operatorname{net}_{i}(t)+b_{i}\right)
\end{aligned}
$$

where $a_{i}(t)$ is the average spike output of unit $i$ at time $t$, net ${ }_{i}(t)$ is the net input (excitatory minus inhibitory input) for unit $i$ at time $t, b_{i}$ is a bias term, and $\sigma(x)$ is the logistic (sigmoidal) function. Finally, the value $w_{i j}$ is the directed weight from CCU $j$ to CCU $i$. The value $\tau$ $(0<\tau \leq 1)$ determines how strongly the activation value (average spiking activity) at the last time point $(t-1)$ is influencing the activity of a unit at the current time point $t$.

Area $\mathrm{M}-<$ retina $>$ contains $256 \times 256$ CCUs representing retinotopically organized cortical columns signaling physical surface luminance. In $\mathrm{M}-<\mathrm{V} 1>$, the number of CCUs is a factor of four lower as in $\mathrm{M}-<$ retina $>$ (Burt and Adelson, 1983), corresponding to an increased receptive field size. The $\mathrm{M}-<\mathrm{V} 1_{\text {inter }}>$ area is subdivided in 8 layers with each layer representing cells with a specific "contour detection sensitivity" (i.e., a specific combination of orientation sensitivity and contrast polarity). As depicted in Fig. 1, each of the cells in the $\mathrm{M}-<\mathrm{V} 1_{\text {inter }}>$ area receives two inhibitory and two excitatory inputs from $\mathrm{M}-<$ retina $>$, the combination of which creates a receptive field with a specific contour detection sensitivity. Specifically, cells in $\mathrm{M}-<\mathrm{V} 1_{\text {inter }}>$ that receive two excitatory inputs on the left, right, bottom, or upper side of the $2 \times 2$ array of inputs, correspond to respectively left, right, bottom, or top contour detection cells. Although these cells are intermingled within the interblob area of V1, they are displayed in separate layers for clarity. In addition to the input from $\mathrm{M}-<$ retina $>$, each CCU receives (a weak) inhibitory input from its eight direct neighbors within the same layer. This lateral inhibition is modeled as a Gaussian distribution with a weight of -0.3 and a decay of 0.5 . Finally, area $\mathrm{M}-<\mathrm{V} 1_{\text {blob }}>$ integrates the contour information of $\mathrm{M}-<\mathrm{V} 1_{\text {inter }}>$ with the brightness information signaled by area $\mathrm{M}-<$ retina $>$. Each $\mathrm{CCU}$ of this area receives four excitatory connections from $\mathrm{M}-<$ retina $>$, which is modulated by inhibitory or excitatory input from $\mathrm{M}-<\mathrm{V} 1_{\text {inter }}>$, as depicted in Fig. 1. Furthermore, a lateral spreading (with weight 0.3 and decay 0.5 ) was implemented in $\mathrm{M}-<\mathrm{V} 1_{\mathrm{blob}}>$. This connection scheme leads to edge-induced brightness filling-in in area $\mathrm{M}-<\mathrm{V} 1_{\mathrm{blob}}>$. Thus, whereas area $\mathrm{M}-<$ retina $>$ represents physical luminance information, neural activity in area $\mathrm{M}-<\mathrm{V} 1_{\mathrm{blob}}>$ should be more akin to the perceived brightness of visual input. The connection weights from $\mathrm{M}-<$ retina $>$ to $\mathrm{M}-<\mathrm{V} 1_{\text {inter }}>$ and from $\mathrm{M}-<$ retina $>$ to $\mathrm{M}-<\mathrm{V} 1_{\text {blob }}>$ were 4 , and 0.5 , respectively. In addition, the first and second halves of the $\mathrm{M}-<\mathrm{V} 1_{\text {inter }}>$ layers were connected to $\mathrm{M}-<\mathrm{V} 1_{\text {blob }}>$ with a weight of 4 and -4 , respectively.

To increase the comparability between the two data sets in the temporal dimension, we transformed the CCU activity from spiking to BOLD signals by applying the following computations on the network activity: First we calculated the integrated synaptic activity, net $t_{i}^{\text {abs }}$, as the sum of the absolute activity arriving via excitatory and inhibitory synapses at CCU $i$ (which differentiates neta ${ }_{i}^{\text {abs }}$ from the standard 'netto' input net):

net $_{i}^{\mathrm{abs}}=\left|\sum w_{i j}^{\mathrm{ex}} a_{j}+\sum w_{i j}^{\mathrm{inh}} a_{j}\right|$

Subsequently, we computed the proto-fMRI signal by integrating synaptic and spike activity (akin to the local-field potentials, LFP):

$a_{i}^{\mathrm{fMRI}}=\lambda \operatorname{net}_{i}^{\mathrm{abs}}+(1-\lambda) a_{i}$

with the weight factor $\lambda$ set to 0.8 , as LFP and fMRI data have been shown to predominantly reflect (subthreshold) synaptic activity (Logothetis et al., 2001; Maier et al., 2008). Then, we transformed this signal into the fMRI signal $y_{i}$ by convolving it with a two-gamma hemodynamic response function $\mathrm{HRF}_{i}$ (Friston et al., 1998):

$y_{i}=\operatorname{HRF}_{i}\left(a_{i}^{\mathrm{fMRI}}\right)$

We finally mimicked physiological, measurement, and instrumental noise in the BOLD response by incrementally adding $30 \%$ of white Gaussian noise $(N(t))$ (Roebroeck et al., 2005). Note that for any time instants $t_{i}$, the corresponding $N\left(t_{i}\right)$ values are independent Gaussian random variables:

$y_{\text {noise }}=y_{i}+N(t) \quad$ with $E[N(t)]=0$

The network performed ten runs (460 volumes each) with the brightness induction design and one run with the brightness control design (290 volumes each) similarly to the human fMRI study described below.

\section{fMRI data}

Seven healthy adults participated in the fMRI brightness induction, control, and (stimulus) localizer experiments. In addition to six functional runs for the brightness induction and control conditions (460 volumes each), two functional runs (290 volumes each) were acquired to localize the retinotopic representation of the inducer and probe regions using standard retinotopic mapping procedures.

Standard $\mathrm{T}^{*}$-weighted gradient-echo echo planar imaging were acquired (3 T Siemens Allegra; TR/TE: 1000/30 ms; flip angle: $90^{\circ}$; slice thickness: $2 \mathrm{~mm} ; 128 \times 128$ matrix) and submitted to standard preprocessing steps using BrainVoyager QX (Brain Innovation, The Netherlands). Based on the independent stimulus localizer patchesof-interest (POIs) were defined for each subject, constituting the retinotopic representations of the probing region and abutting inducer stimulus surfaces in area V1. Conditional effects between V1 POIs time courses were analyzed in a similar fashion as the simulated $\mathrm{M}-<\mathrm{V} 1_{\text {blob }}>$ activity as described in the next section. In addition, a high-resolution anatomical scan (T1; MPRAGE) was measured for each participant, and a cortical mesh (constituting the white-grey matter boundary of the cortical sheet) was reconstructed, inflated, and flattened (see Fig. 6 for an example). Additional details are described in van de Ven et al. (in preparation). 
fMRI and neural net integration in the common brain space framework

Fig. 2 shows the essential features of the CBS approach. To enable the direct comparison between our model's predictions and experimental fMRI data, we projected our model on a cortical mesh of a subject who participated in our fMRI study (left side of Fig. 2). On this mesh, we marked the subject-specific V1 POIs (brown, green, and blue patches in Fig. 2). Then, we connected each CCU with the topographically corresponding patch in the visual cortex via a networkbrain link (NBL; see right side of Fig. 2). Via these NBLs, CCU activity can be directly projected on the cortical sheet at each time step of a running simulation.

Thereby, complete time series of network activity can be created with a similar data format as measured fMRI time series. This enables the analyses of activity changes in simulated and measured data using identical analyses methods. To illustrate this, we created time series of

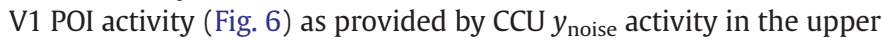
quadrant of $\mathrm{M}-<\mathrm{V} 1_{\text {blob }}>$ (Fig. 2), plotted event-related averages (Fig. 7), run a general linear model (GLM; Fig. 8), and compared results based on the observed $\mathrm{V} 1$ and simulated $\mathrm{M}-<\mathrm{V} 1_{\mathrm{blob}}>$ data (Fig. 9). The GLM design matrix contained a single predictor to model luminance changes (relative to grey level during rest periods) and was convolved with a two-gamma hemodynamic impulse response function to account for the hemodynamic delay.

All modeling was performed with Neurolator 3D (Brain Innovation BV, Maastricht, The Netherlands), a neural network simulation software package, which can be conveniently interfaced with fMRI data analyses software such as BrainVoyager QX (Brain Innovation BV, Maastricht, The Netherlands).

\section{Results}

The current model provides a simulation of brightness processing in the primary visual cortex (V1). The network's connection scheme is explained in Fig. 3, in which the model areas display schematic activation profiles in response to a stimulus with inducers that are brighter than the probing region. Depicted grey levels indicate the strength of CCU activity. Several CCUs are enlarged and shown on top of the activity profiles to illustrate the activity flow. The first layer, $\mathrm{M}-<$ retina $>$, represents physical luminance information. This information is processed in two subsequent stages: In the first stage, contours are extracted from local luminance discontinuities, which are signaled from $\mathrm{M}-<$ retina $>$ to $\mathrm{M}-<\mathrm{V} 1_{\text {inter }}>$. Activity in $\mathrm{M}-<\mathrm{V} 1_{\text {inter }}>$ depends on the contour detection sensitivity, specified by the connection pattern (see colored figures accompanying $w_{1}$ weights). An $\mathrm{M}-<\mathrm{V} 1_{\text {inter }}>\mathrm{CCU}$ connected to four $\mathrm{M}-<$ retina $>$ CCUs that represent a homogeneous surface will receive a balanced input of excitation and inhibition. In contrast, cells at a surface boundary will mainly excite or inhibit the corresponding $\mathrm{M}-<\mathrm{V} 1_{\text {inter }}>$ cell if the excitatory connections represent the lighter or darker surface, respectively. In this figure, the $\mathrm{M}-<\mathrm{V} 1_{\text {inter }}>$ layers with top (left sheet) and bottom (right sheet) contour detection cells are shown, but activation mechanisms are similar for the other six layers. The top and bottom contour detection layers have opposite activity profiles, which leads to antipodal activations at the subsequent stage.

In the second stage, this contour-related activity modulates luminance-related activity in $\mathrm{M}-<\mathrm{V} 1 \mathrm{blob}>$. CCUs of $\mathrm{M}-<\mathrm{V} 1_{\text {inter }}>$ with high activity (the white cubes) inhibit corresponding cells in the next layer according to the depicted connection pattern. Thus, active CCUs in the top contour detection (left) sheet induce a downward inhibition, whereas active CCUs in the bottom contour detection (right) sheet induce an upward inhibition. This results in an inhibition of the probing region, corresponding to the decreased perceived brightness of this region. The brightness illusion is observed both when surroundings are brighter or darker: that is, a grey area appears to be darker in bright surroundings, and brighter in dark surroundings, compared to its actual luminance. Fig. 3 illustrates network behavior when inducers are brighter than the probe region. However, our network is also able to correctly respond to stimuli with dark inducers. As shown in Fig. 1, layers $2-5$ of $\mathrm{M}-<\mathrm{V} 1_{\text {inter }}>$ are identical to layers $6-9$, except for the polarity of their connection to $\mathrm{M}-<\mathrm{V} 1_{\mathrm{blob}}>$. Therefore, when inducers become darker, active CCUs in layers 2 and 3 will increase activity in the probing region of $\mathrm{M}-<\mathrm{V} 1_{\mathrm{blob}}>$, as opposed to the inhibitory influence of layers 6 and 7 as shown in Fig. 3 .

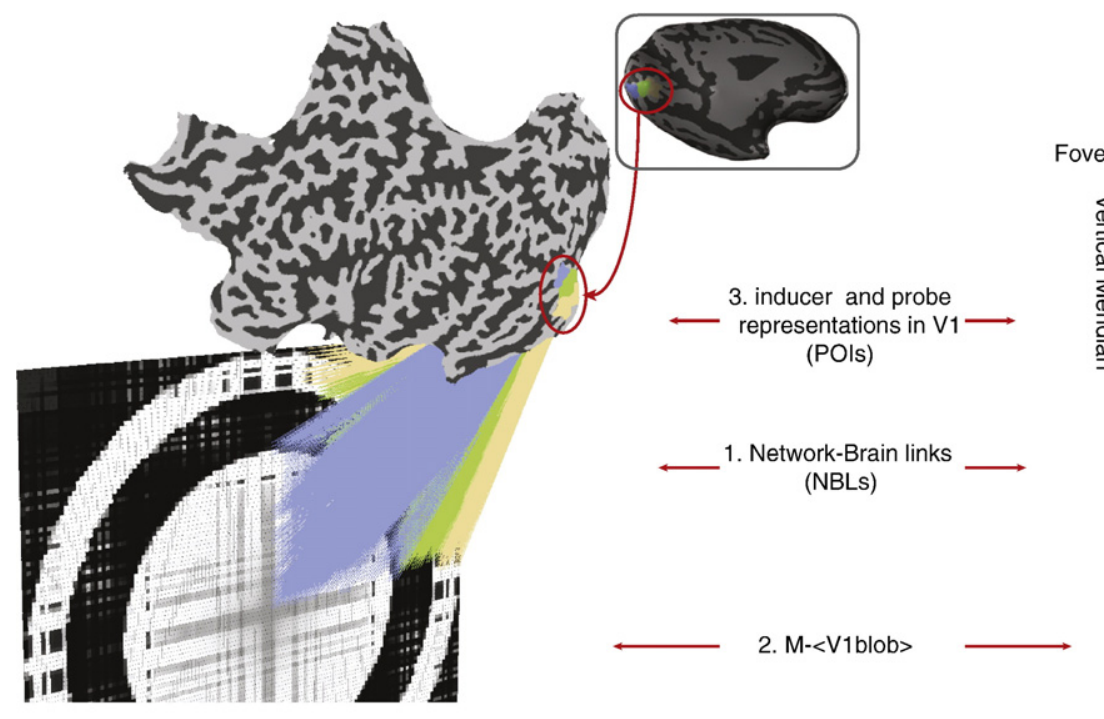

Horizontal Meridian

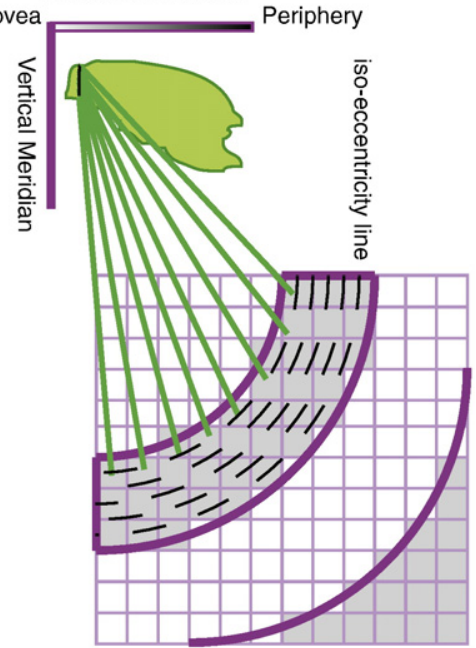

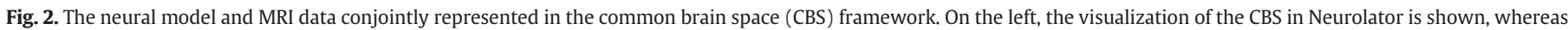

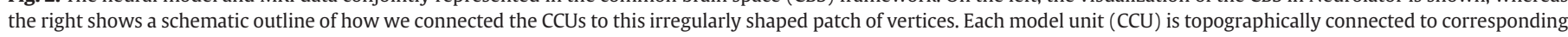

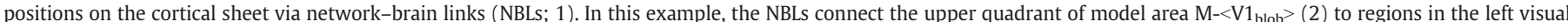

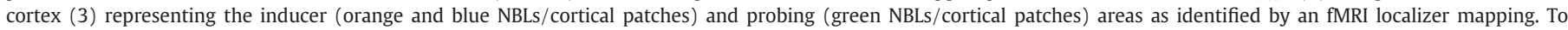

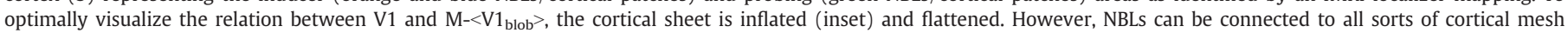
representations. Note that this example shows connections from initial tests, modeling input to a stimulus with different annulus widths than used in the final simulations. 


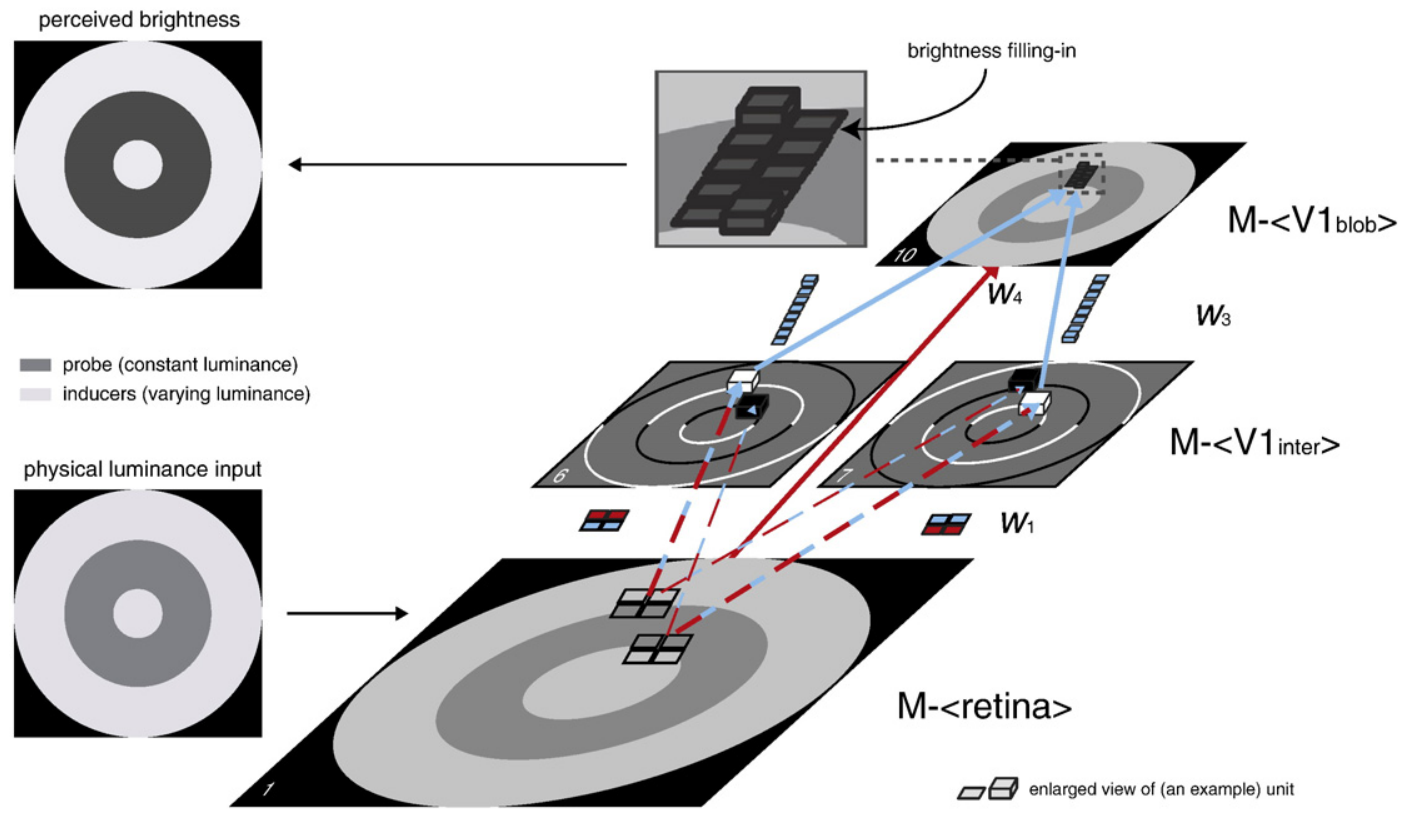

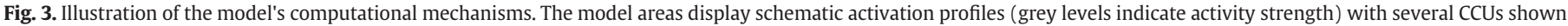

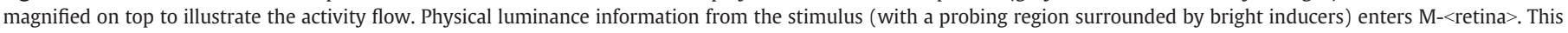

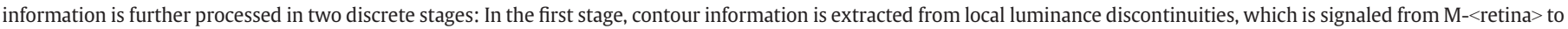

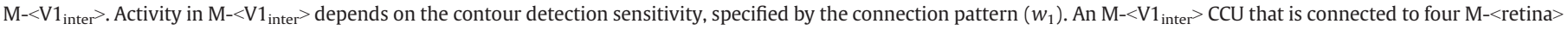

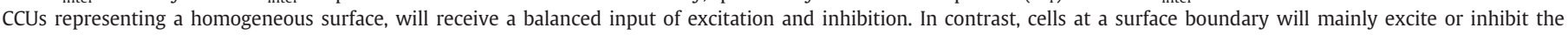

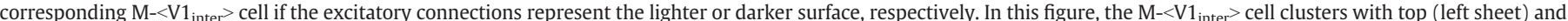

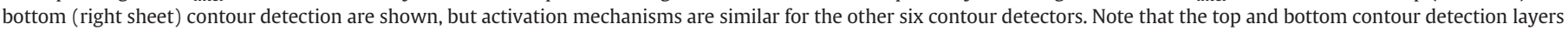

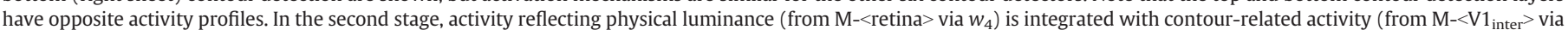

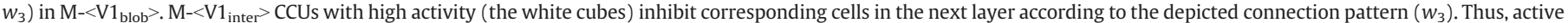

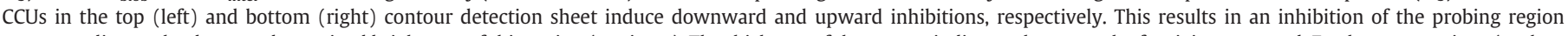

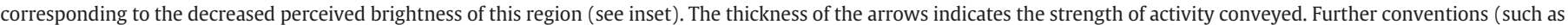
numbering of layers) are identical to Fig. 1.

Activity in $M-<$ retina $>$ and $M-<V 1_{\text {blob }}>$ reflect physical and perceived brightness, respectively

Fig. 4 shows an example of the model's behavior. As in Fig. 3, activity in $\mathrm{M}-<$ retina $>$ reflects the physical luminance of the image, which provides information on luminance discontinuities to model area $\mathrm{M}-<\mathrm{V} 1_{\text {inter }}>$. The activity profile of layers 2 to 9 , constituting $\mathrm{M}-<$ $\mathrm{V} 1_{\text {inter }}>$, emphasizes the contours of the surfaces, whereby the distribution of low (black) and high (white) activations depend on

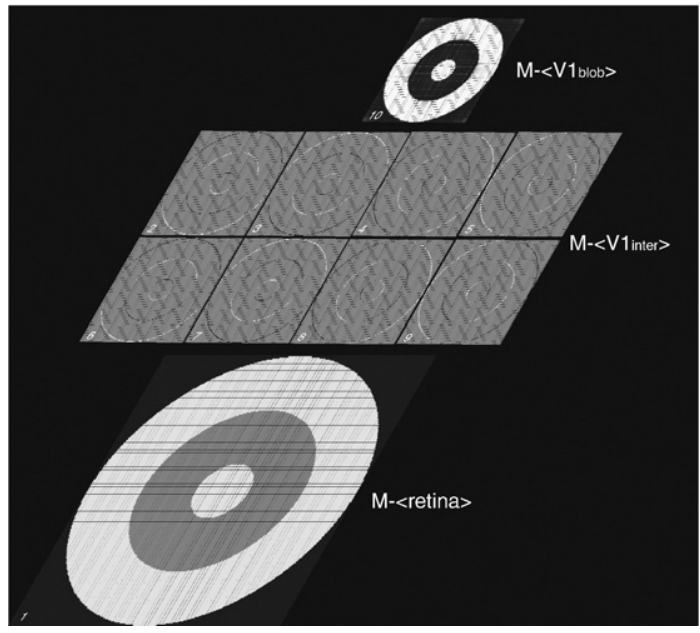

Fig. 4. Activity in the network. When luminance values of a stimulus with bright inducers (see lower left image in Fig. 3 ) enter the network, activity in model area $\mathrm{M}-<$ retina $>, \mathrm{M}-<\mathrm{V} 1_{\text {inter }}>$, and $\mathrm{M}-<\mathrm{V} 1_{\text {blob }}>$ reflect physical brightness, contours, and perceived brightness, respectively. Grey values indicate response strength (black $=$ no activity, white $=$ maximum activity). See Figs. 1 and 3 for network details. the contour detection sensitivity of the specific layer. This contour information subsequently modulates activity in layer $\mathrm{M}-<\mathrm{V} 1_{\mathrm{blob}}>$, leading to decreased activity in the probing region.

Fig. 5 provides the opportunity to directly compare the physical and perceived luminance, as reflected by $\mathrm{M}-<$ retina $>$ and $\mathrm{M}-<\mathrm{V} 1_{\text {blob }}>$, respectively. Here, we show the network's behavior for two stimuli at the extremes of the luminance continuum, whereas Fig. 6 gives information on the model's performance along the entire continuum. When comparing activity in the probing region of $\mathrm{M}-<$ retina $>$ and $\mathrm{M}-<\mathrm{V} 1_{\text {blob }}>$ in the first row of Fig. 5 , one can clearly see that activation is reduced in the second area, corresponding to a decreased brightness percept. The opposite is true for the second row, in agreement with an increase in perceived brightness of a grey surface in dark surroundings. So, although the equal luminance of the probing region in both stimuli elicited an identical activation in $\mathrm{M}-<$ retina $>$, the activation in $\mathrm{M}-<\mathrm{V} 1_{\mathrm{blob}}>$ greatly differs, due to contextual influences.

Activity in $M-<V 1_{b l o b}>$ corresponds to hemodynamic correlates of perceived brightness in $\mathrm{V} 1$

The NBLs in the CBS framework connect each CCU to its corresponding cortical patch representing the inducer and probing regions. Moreover, they allow the direct projection of network activity on the cortical sheet.

We connected the cortical mesh to a running neural network, and created time series of $\mathrm{M}-<\mathrm{V} 1_{\mathrm{blob}}>$ activity changes that were projected on the corresponding cortical representation (see Fig. 2) Fig. 6 displays the average time series of the simulated data in the localized probe and inducer POIs. As shown in Figs. 6A and 6B the synaptic activity (net $t_{i}^{\mathrm{abs}}$ ) in the inducer area is in-phase with the actual luminance changes of the inducer. In contrast, activity changes in the probing region are in anti-phase, robustly mimicking the 


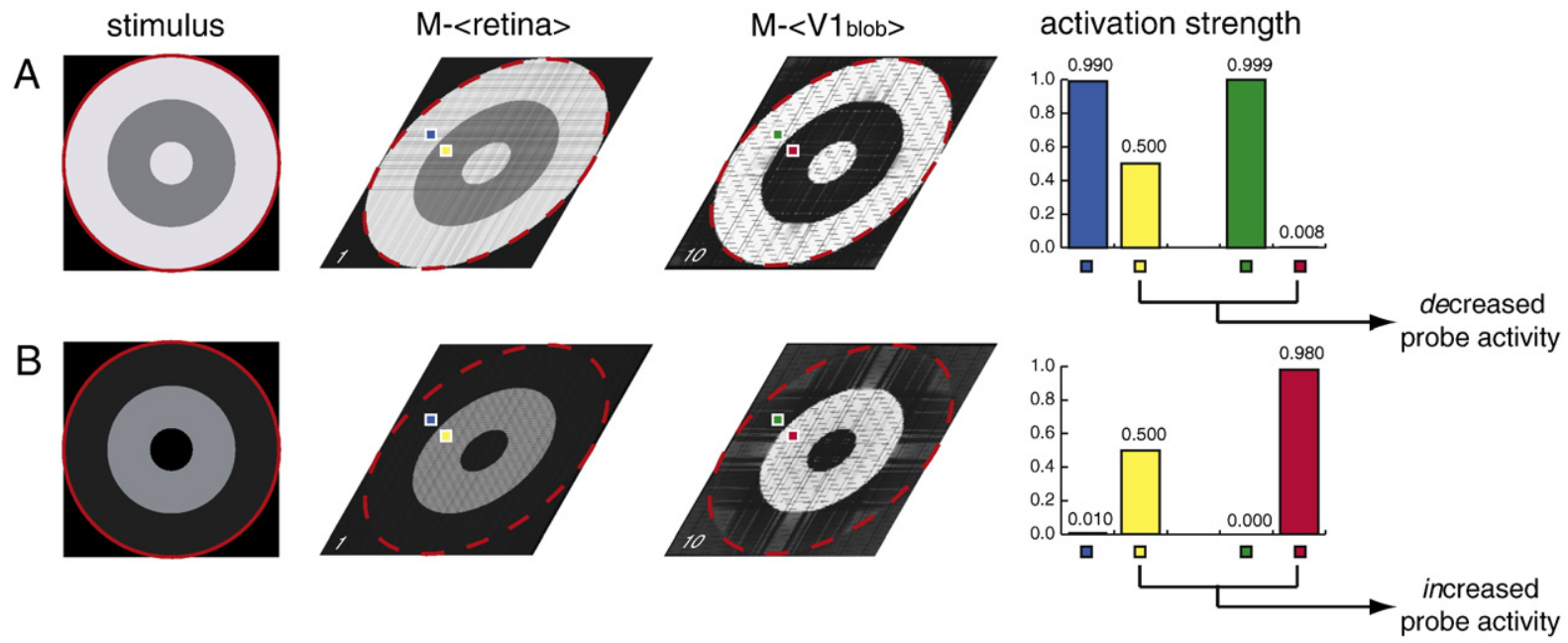

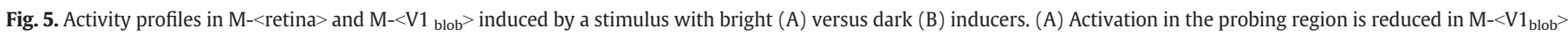

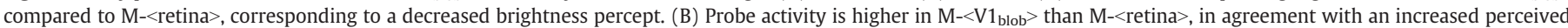

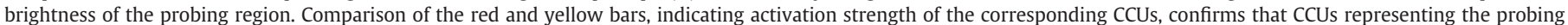
region elicited an identical activation in $\mathrm{M}-<$ retina $>$, whereas these activations diverge in $\mathrm{M}-<\mathrm{V} 1_{\mathrm{blob}}>$. Note that the (dashed) red circle is for illustration purposes only.

perceived brightness changes. The second column of Fig. $6 \mathrm{~B}$ presents the simulated fMRI signal ( $\left.y_{\text {noise }}\right)$, which is obtained by convolving the spike data with an HRF function and by adding Gaussian noise.

Fig. 7 shows the event-related averages of this signal in the illusory (left column) and control (right column) condition when the luminance of the inducers gradually increase ("up"; green line) or increase ("down"; blue line). In line with the activity patterns in Fig. 6B, the event-related fMRI signals of the up and down period are in anti-phase in the inducer and probe POI. This anticorrelation between inducer and probe POI activity also emerges in the statistical map: As shown in Fig. 8, voxel-wise regression clearly segregates the inducer and probe POIs (compare Figs. 8A and B), indicating that when activity increases in the inducer POI, it decreases in the probe POI and vice versa.

This anti-phasic activity of inducer regions following luminance changes, and of probe regions corresponding to perceived luminance, is very obvious when the amplitudes of the event-related averages are plotted, as is done in Fig. 9: In the "up" condition (green bars), inducer POI activity goes up (in line with increasing inducer luminance), whereas probe POI activity goes down (although probe luminance is fixed). The reverse is true in the "down" condition (blue bars), showing that increased as well as decreased illusory brightness changes are reflected by hemodynamic activity. This reversal effect of probing region activity was absent in the control condition (i.e., fixed black probing region). Moreover, Fig. 9 provides a direct comparison between POI activity of simulated and empirically obtained fMRI data. In the first case, POI activity represents data of probe or inducer CCUs in model area $\mathrm{M}-<\mathrm{V} 1_{b_{b l o b}}>$, which are projected to the corresponding mesh vertices by NBLs (see Fig. 2 and Methods for details). In the second case, POI activity reflects activity of real fMRI measurements, which were aligned to the corresponding anatomical cortical vertices. The similarity of the amplitude patterns in the left (simulations) and right (empirical data) plots of Fig. 9 suggest that $\mathrm{M}-<\mathrm{V} 1_{\text {blob }}>$ activity can predict observed activity in human V1 fairly well.

\section{Discussion}

In this paper, we apply a new approach to compare empirical data and model predictions in a common brain space (Goebel and Horwitz, in preparation; Goebel and De Weerd, 2009). We suggest that this approach can facilitate hypothesis testing, thereby contributing to deciphering cortical circuits involved in surface brightness perception and other perceptual and cognitive abilities. Below, we discuss the potential neural mechanisms of brightness perception and how we and others have modeled these mechanisms. Finally, we discuss current possibilities of the CBS framework as well as future perspectives.

\section{Neural mechanisms of brightness perception}

At a subcortical level, the neural mechanisms of contour and surface perception are relatively well understood: The visual image is filtered by center-surround antagonistic RFs of retinal ganglion and lateral geniculate nuclear (LGN) cells, leading to image normalization. Since normalization leads to a strong emphasis on discontinuities in luminance distribution, the primary visual cortex (V1) mainly receives contour-rather than surface-related information. Most models suggest that at the cortical level surfaces have to be reconstructed from local contour information (Grossberg, 1987a,b, 2003), which can also explain why brightness percepts can differ from what would be expected based on luminance distributions in stimuli generating brightness illusions. However, not all surface information is lost in the subcortical processing stage: The LGN (Rossi et al., 1996), V1 blobs (Roe et al., 2005), and V2 thin stripes (Ts'o et al., 2001; Wang et al., 2007) contain neurons that are readily stimulated when large, homogenous stimuli are placed over their RFs. The presence of such 'Luxotonic' (Kayama et al., 1979) or 'Type-I' (Kinoshita and Komatsu, 2001) neurons that code absolute luminance was confirmed by others in monkey V1 (Friedman et al., 2003; Huang and Paradiso, 2008; Kayama et al., 1979; Kinoshita and Komatsu, 2001; Maguire and Baizer, 1982; Wachtler et al., 2003) and in cat area 17 (Bonhoeffer et al., 1995; Shoham et al., 1997). Visual illusions offer a valuable tool to study at which stage of processing surface percepts are constructed, as physical and perceived surface features (e.g., brightness or color) can be segregated. The findings above suggest that at least some physical surface information is processed along the subcortical and cortical pathway, but it is less clear at which stages of processing perceived surfaces are represented. LGN activity appears to only reflect physical brightness (Rossi et al., 1996), whereas divergent observations are reported for V1 which might be due to the different visual illusions that were used. Studies investigating the Craik-O'Brien-Cornsweet illusion (Cornsweet, 1970) observed mainly perceived brightness correlates in V2 (Hung et al., 2001; Perna et al., 2005; Roe et al., 2005), although V1-V2 interactions significantly contribute (Hung et al., 2007; and see Boyaci et al., 2007 for Cornsweet effects in V1). In contrast, activity related to neon color spreading has been established 
A

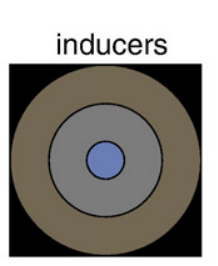

black

stimulus luminance
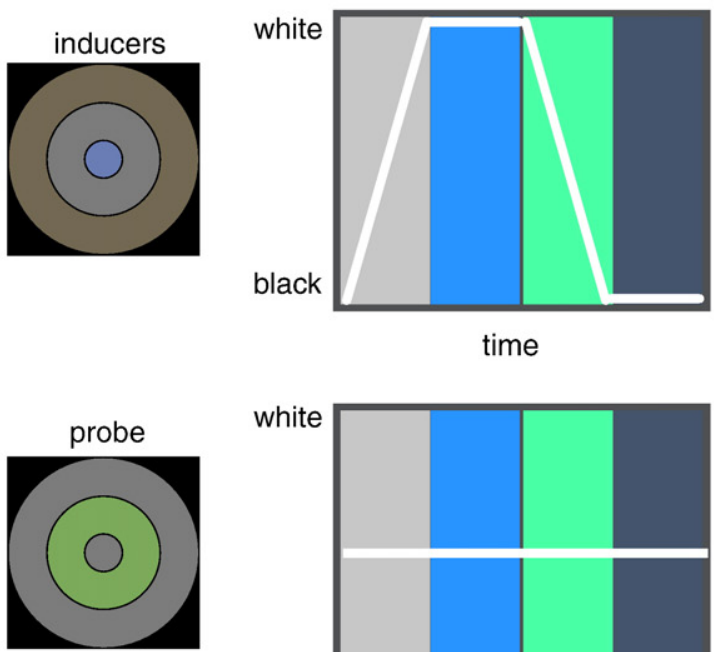

black

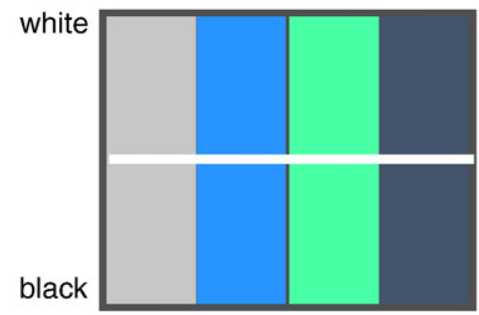

time brightness percept

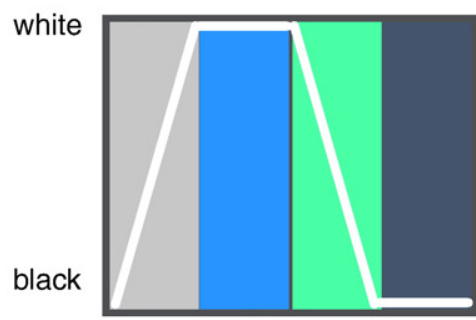

time

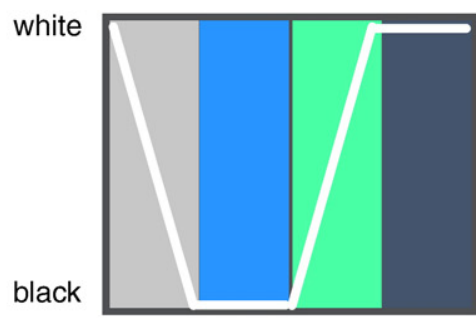

time simulated neural activity

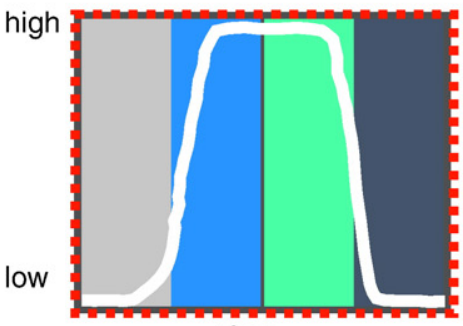

time

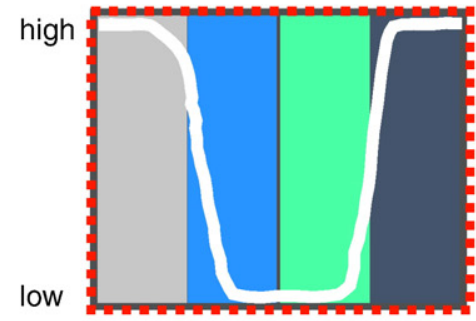

time

luminance of inducers:

$\mathrm{B}$

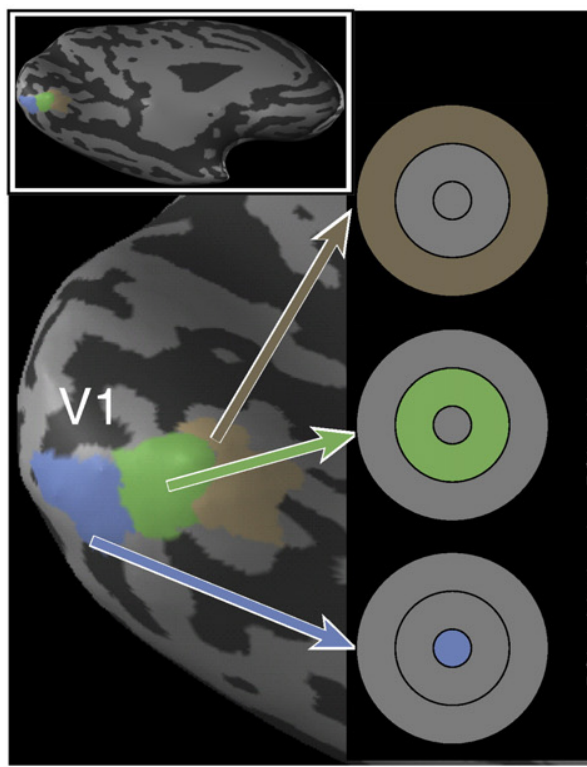

$\mathrm{M}-<\mathrm{V} 1_{\mathrm{blob}}>\mathrm{LFP}$ activity
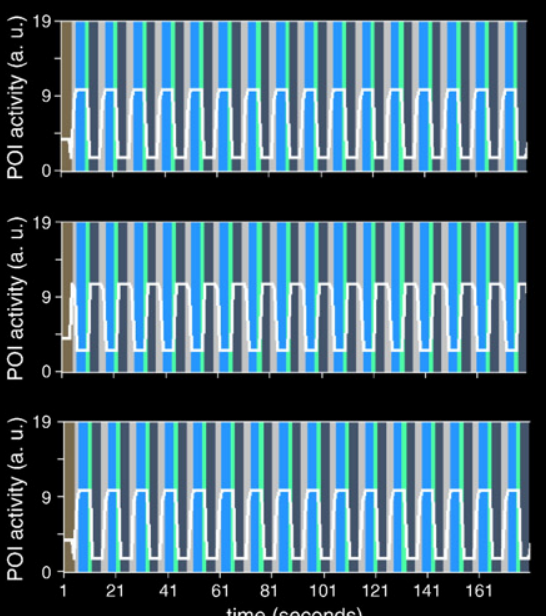

time (seconds)
$\mathrm{M}-<\mathrm{V} 1_{\text {blob }}>\mathrm{fMRl}$ activity
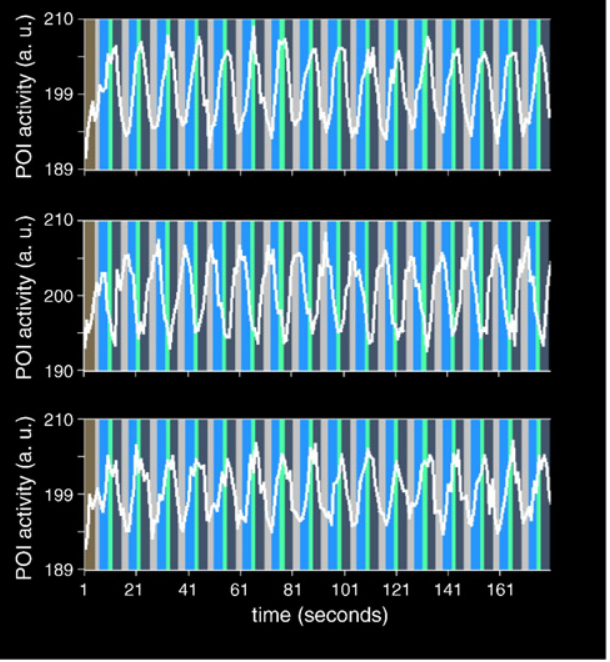

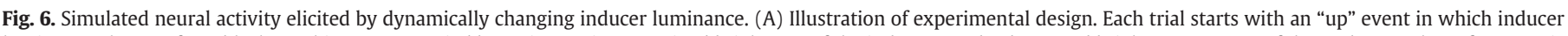

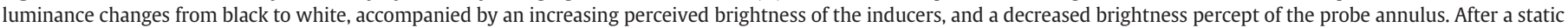

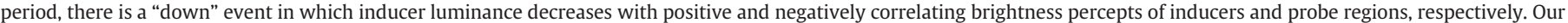

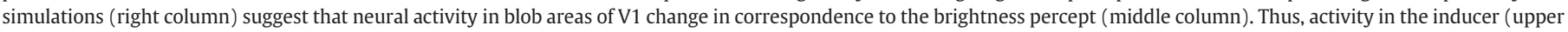

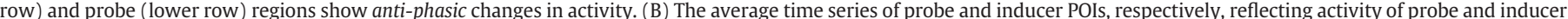

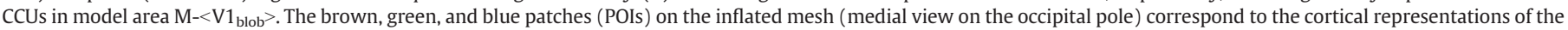

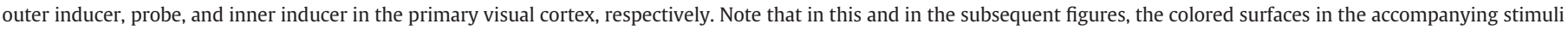

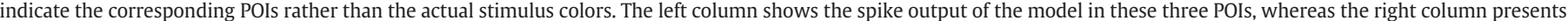

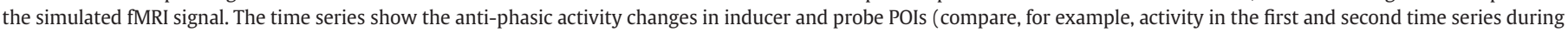
the blue interval).

in monkey V1 (Murakami et al., 1997; Komatsu et al., 2000) and human V1 (Sasaki and Watanabe, 2004). Also for brightness induction, which is the type of brightness illusion used in the present study, correlates of perceived brightness have been observed in V1 (Pereverzeva and Murray, 2008; van de Ven et al., in preparation; but see Cornelissen et al., 2006) in V1. Together, these findings suggest that, at least for brightness induction, both physical as well as perceived brightness-related surface information is represented in V1.
Note that neural activity underlying brightness perception can be modulated by cognitive factors. For example, Sasaki and Watanabe (2004) showed that neural correlates of color spreading are constrained to V1 when attention is controlled, whereas otherwise correlates of spreading effects can be found in extrastriate areas as well. Surprisingly, Mendola et al. (2006) observed decreased activity in V1 and V2 during luminance filling in. This discrepant finding might be related to the different paradigm used in that study (i.e., Troxler's 

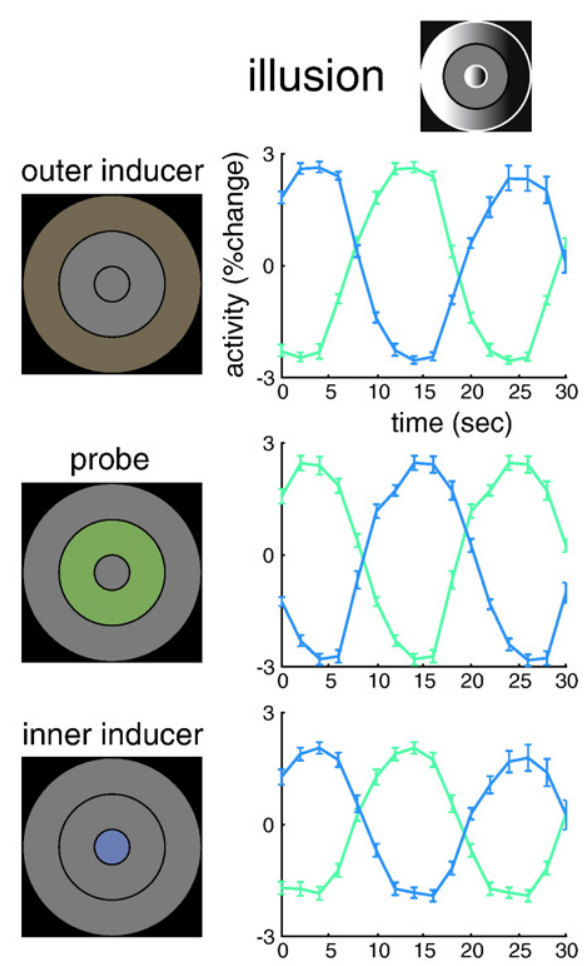
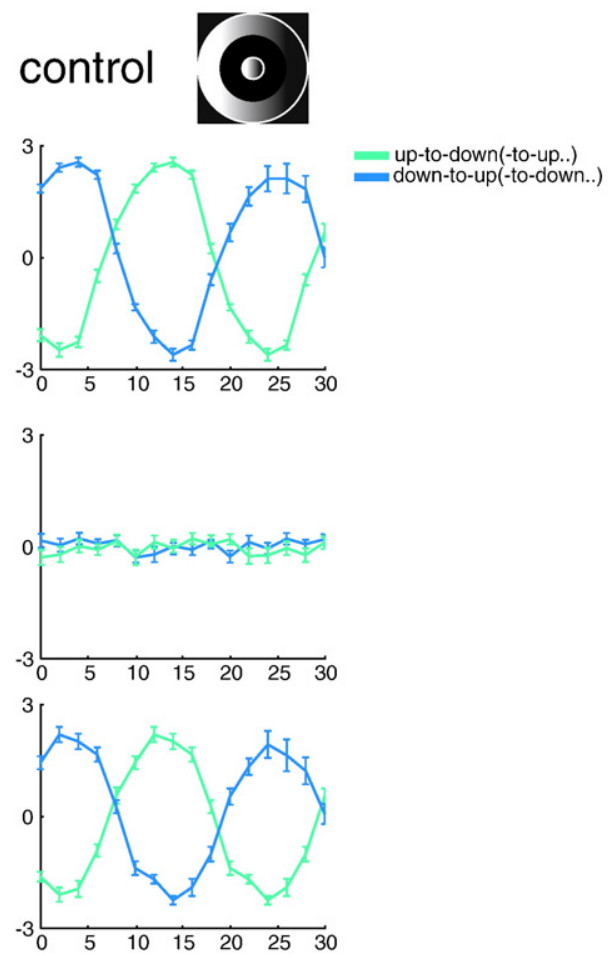

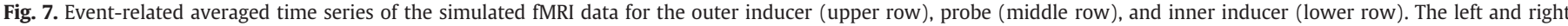

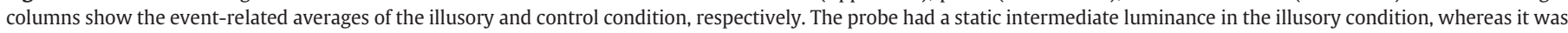

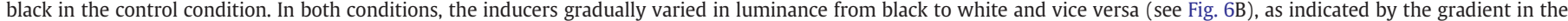

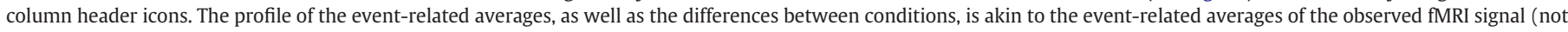

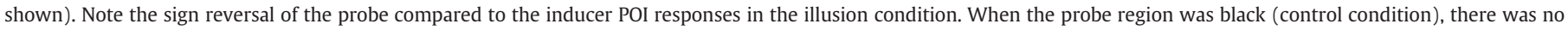
probe POI activity, in line with the lack of perceived brightness changes. Errorbars indicate 1 standard error of the mean (SEM).

fading; Troxler, 1804), which might have engaged higher-level processes (indicated by the additional activations observed in cortical association regions).

Contour and surface information appear to be processed in two segregated, but interacting, streams: Neurons in V1 blobs respond to

A Inducer and probe representations

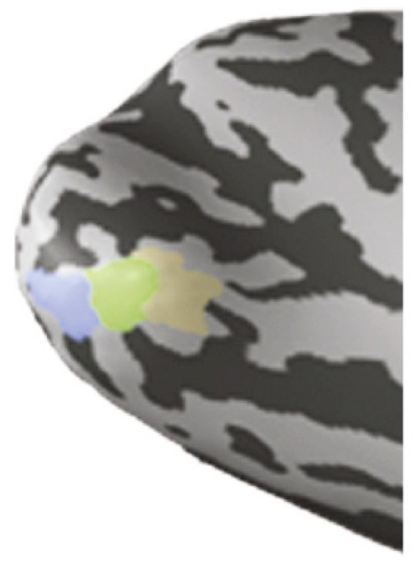

B Activity changes reflecting modulation of inducer luminance

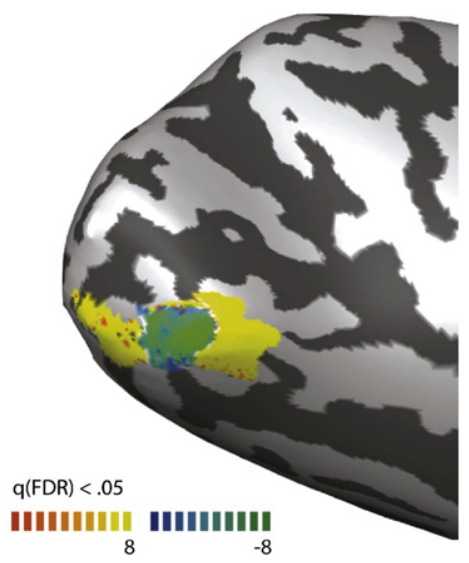

Fig. 8. (A) Medial view on the occipital pole of an inflated cortical mesh. The brown green, and blue patches (POIs) correspond to the cortical representations of the outer inducer, probe, and inner inducer in V1, respectively. (B) Results of contrasting V1 activity (with the map constraint to the V1 POIs) of the network simulations that is inphase (red-yellow) and in counterphase (blue-green) with the changing luminance of the inducers. Note that the borders where in-phase and counterphase activity segregate (in B) coincident with the borders between the probe and inducer regions (in A). homogenous surfaces, whereas V1 interblob regions contain neurons that are preferentially stimulated by oriented contrasts (e.g., contours and edges). Likewise, neurons in V2 thin stripes areas react to surfaces (Roe et al., 2005), while V2 interstripe regions show preferential responses to lines and edges (Bartfeld and Grinvald, 1992; Blasdel et al., 1985; DeYoe and Van Essen, 1988; Fitzpatrick et al., 1985; Hubel and Livingstone, 1987; Landisman and Ts'o, 2002; Lu and Roe, 2008; Yabuta and Callaway, 1998). Taken together, these data support the idea that there are separate (but interacting) processing streams for contour and surface processing, with a blob/thin stripe system for surface representation and an interblob/interstripe system for contour representation. For a more extensive review on neural mechanisms of brightness perception, the reader is referred to the existing literature (Pessoa and De Weerd, 2003; Goebel and De Weerd, 2009; Neumann et al., 2001).

\section{Our model and other computational models of brightness perception}

Our model is based on empirical research discussed in the previous section. An essential feature in our model's architecture is the modulation of physical brightness information represented by "luxotonic" cells in $\mathrm{M}-<\mathrm{V} 1_{\text {blob }}$, by contour information in $\mathrm{M}-<\mathrm{V} 1_{\text {inter }}>$. Results showed that our model performs well in simulating dynamical changes in perceived surface brightness. It was able to predict illusory brightness changes in a grey area of constant luminance when brightness of its surroundings was dynamically varied. Moreover, the activation changes in CCUs representing the probing region varied in a similar fashion as the topographically corresponding V1 activity in a subject presented with the same stimulus design. This suggests that V1 plays a role in generating surface brightness percepts, which is in agreement not only with our own fMRI data (van de Ven et al., in preparation) and those of others (Pereverzeva and Murray, 2008) but 


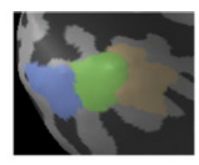

outer inducer

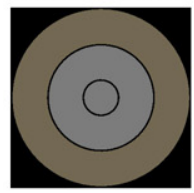

probe

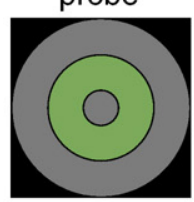

inner inducer

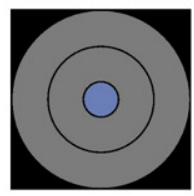

$\mathrm{M}-<\mathrm{V} 1_{\text {blob }}>$ activity
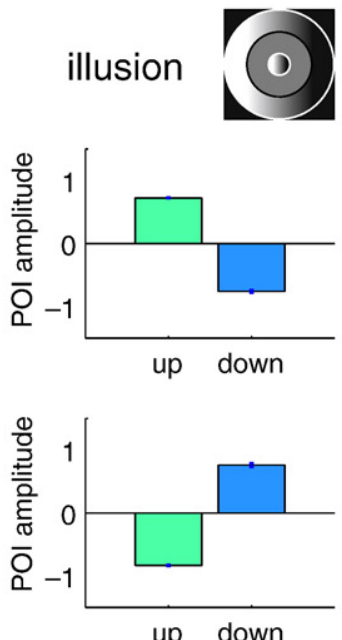

up down

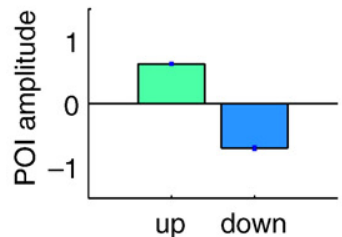

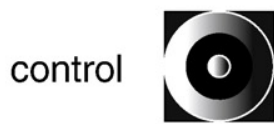
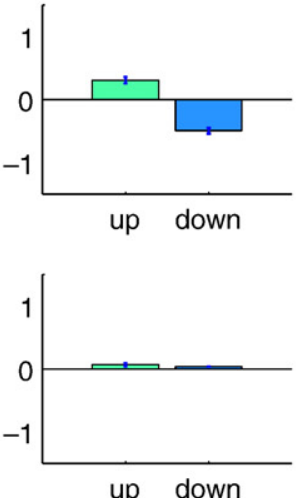

up down

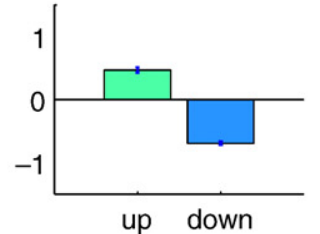

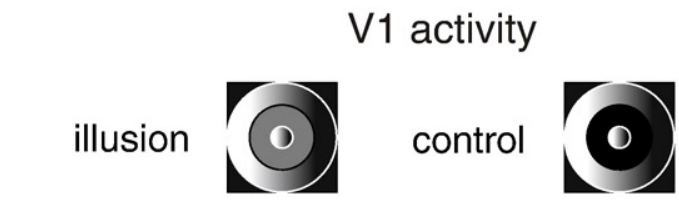
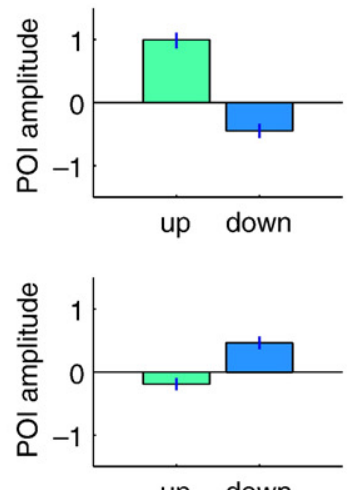

up down
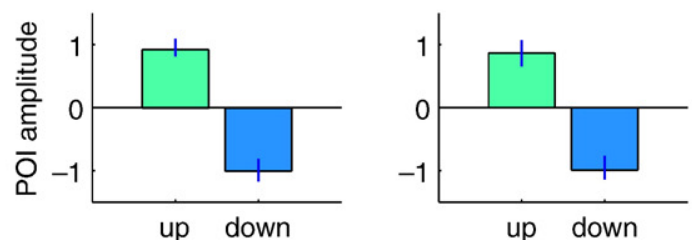

measured fMRI data

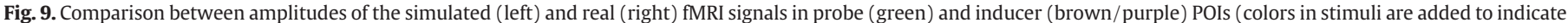

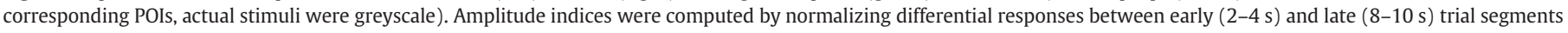

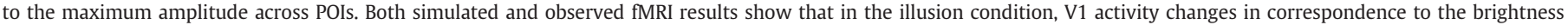

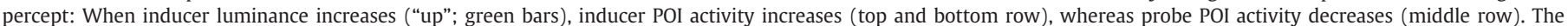

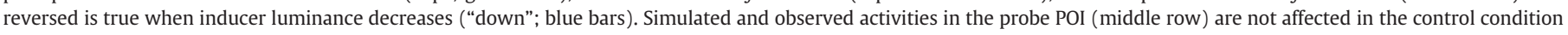
when the probe region is black. Error bars indicate 1 SEM.

also with neurophysiological findings in the cat (Rossi et al., 1996; Rossi and Paradiso, 1999).

Our modeling approach is rather different from previous modeling approaches. Our work started from the assumption that surface brightness is explicitly represented in V1 by "luxotonic" cells that signal surface information. This hypothesis differs from proposals that surface perception relies on 'symbolic tagging' (Denett, 1991). According to the symbolic tagging theory, surface qualities are not encoded in retinotopic areas. Instead, surfaces are implicitly (symbolically) represented as a lack of discontinuities in between identified surface boundaries, and surface encoding takes place entirely at later visual stages, where surfaces form an integral aspect of object representations. In addition, our surface representation at the earliest cortical stages of visual processing is also not in agreement with multiscale spatial filtering theories assuming that brightness perception does not require an explicit spreading mechanism (Blakeslee et al., 2005; Dakin and Bex, 2003; McCourt, 1982; Purves et al., 1999; Stromeyer et al., 1984). Based on multiscale spatial filtering theory, some models were developed to simulate brightness assimilation (Barkan et al., 2008; Blakeslee and McCourt, 1999, 2001, 2004; Otazu et al., 2008), such as in the classic White's effect (White, 1979). The most well-established model in this category is the oriented difference-of-Gaussians (ODOG) model of Blakeslee and McCourt (1999, 2001, 2004) that performs an oriented multiscale spatial filtering of input and a subsequent global contrast normalization to equalize responses at each orientation across the visual field. This model can simulate a range of brightness illusions (Blakeslee and McCourt, 2004). Although we do not model receptive fields (RFs) with oriented multiscale filters, the RFs in our model are orientationspecific. In addition, these RFs have excitatory and inhibitory subzones, which effectively produce local normalization. Yet, although RF creation in the current model thus already, in some sense, share similarities with the approach of Blakeslee and McCourt (2004), we will implement Gabor filters (Jones and Palmer, 1987) in future versions of our model to simulate V1 responses even more accurately. Although differences of Gaussians mimic retinal ganglion responses properly (Rodieck, 1965), other aspects of the Blakeslee and McCourt (and related) models such as the global normalization across orientations might be neurally less plausible. Interestingly, a recent neuroimaging study of Kay et al. (2008) used multiscale spatial filtering to decode natural scene processing in human visual cortex. In the first stage of the fMRI experiment, they recorded fMRI responses in V1-V3 to 1750 natural images and used these data to estimate a RF model (based on a Gabor wavelet pyramid) for each brain voxel. Subsequently, this model was employed to predict neural responses to 120 novel images, and to identify which image was viewed by finding the best match between model predictions and observed fMRI activity. We believe that our CBS framework provides an excellent context to integrate the modeling efforts like those of Blakeslee and McCourt with advanced neuroimaging analyses such as those employed by Kay et al. (2008).

Our model has some commonalities with the models of Grossberg (Grossberg, 1987a,b, 2003; Grossberg and Todorovic, 1988; Grossberg and Raizada, 2000; see Neumann et al., 2001 for a related approach) in which surfaces are created by a spreading activation of surface features from the contours of the surface inward. However, according to Grossberg's theory, contours initiate surface spreading and all surface information is reconstructed by an interaction between contour information and surface features. Different to our approach, these surface features are sampled from positions with large luminance or color transitions, to discount variable illumination. In our model, on the other hand, we explicitly model luminance-related information of the 
entire surface, based on direct input (modeled as $w_{4}$ ) from the subcortical pathway (i.e., cells in the LGN signaling surface brightness; Rossi and Paradiso, 1999). Subsequently, the surface information represented by these "luxotonic" CCUs is modulated by-rather than reconstructed from-contour information. Arrington (1994) used a simplified version of Grossberg's model to simulate psychophysical findings in the masking experiments of Paradiso and Nakayama (1991), which tested the speed of brightness spreading in a homogeneous bright circle on a black background, by disrupting the inward spread with a masking stimulus. Arrington's model contained only four neuronal layers: an On-FCS and an Off-FCS layer modeling retinal cells with DOG RFs and one BCS layer in which "boundary cells" are activated at locations were On-FCS and Off-FCS activations are spatially adjacent. Finally, there is the filling-in layer where brightness spreading by FCS input is regulated by parallel BCS input. This simple but elegant model was able to simulate, with a range of masks, the brightness percepts observed by Paradiso and Nakayama (1991). The model of Arrington is, to our knowledge, the only other computational model that models brightness induction using a homogenous stimulus (which can be compared to our homogenous probe region). However, whereas Arrington's model aims to simulate the rapid (i.e., in millisecondrange) brightness filling-in in a static stimulus with fixed luminance, our model attempts to simulate dynamic changes in fMRI activity induced by slow (i.e., in second-range), continuous luminance changes in a dynamic stimulus. These different objectives led to different modeling choices, making it difficult to directly compare our model to that of Arrington or, in fact, to all other models as none of them used-to our knowledge-dynamically changing stimuli.

As the present paper represents a 'proof of principle', we deliberately chose a simple network architecture that focuses on a limited set of mechanisms at a large-scale level. Although it is interesting to see that this limited model has sufficient features to mimic empirically observed fMRI activity, it is clear that we did not implement many relevant principles of neural processing in early visual areas, such as orientation and spatial frequency tuning, or processing in pre-striate processing pathways. Furthermore, although our and other models (e.g., Heitger et al., 1998) show that appropriate contour detection can be obtained with solely feedforward and horizontal connections, boundary detection can be performed faster and more reliable by adding feedback connections (Jehee et al., 2007; see also Roelfsema et al., 2002). Finally, we modeled only V1 as we (van de Ven et al., in preparation) and others (Pereverzeva and Murray, 2008) observed the strongest fMRI correlates of brightness induction in this area. However, V2 appears to play a significant role in computing perceived brightness in the Cornsweet stimulus (Roe et al., 2005). This suggest that both V1 and V2, and especially their interactions (Hung et al., 2007), are important for generating brightness percepts, although their respective contributions seem to shift depending on the studied brightness illusion. Computational modeling offers a promising way to gain insights in the roles of V1 and V2 in brightness perception. By extending our model with recurrent V1-V2 loops, and subsequently comparing observed and simulated fMRI data at V1 and V2 level in different brightness illusion paradigms, a general mechanism of brightness computation might be uncovered that reconciles the various findings.

Large-scale neural models and neuroimaging data in a common brain space: Current possibilities and future perspectives

The approach used in the present paper shows that empirical data and model predictions can be compared in the same brain space. Importantly, when simulated and measured data coexist in the same representational space, the same analysis tools (e.g., univariate GLM, multivoxel pattern analysis, effective connectivity analysis) can be applied to both data sets. Furthermore, dynamic activity patterns of running neural network models can evolve directly on cortex representations or meshes obtained from MRI scans of specific subjects
(Kriegeskorte and Goebel, 2001; Sereno et al., 1995), and therefore, online hypothesis testing against incoming empirical data is possible.

In addition to the manner in which neuromodeling and neuroimaging data were compared in the CBS framework in the present paper, there are several more useful approaches that have not been shown in the present paper. We have confined our comparison to modeled activities in two V1 model layers, which were projected as predicted activities in a single (functionally localized) anatomical region in the human brain (V1). However, comparisons between multiple layers and multiple regions are also possible. In addition, comparisons do not have to be constrained to the visual cortex but can cover different portions of the brain. To study, for example, the observations of Sasaki and Watanabe (2004), the model could be extended with layers representing the frontal eye fields (FEF) and regions in the posterior parietal cortex exerting top-down attentional influences (Corbetta and Shulman, 2002) on brightness computations in the visual areas. Subsequently, we could study how the processing of brightness illusions is modulated by attentional demands in an fMRI and a simulation study. In our CBS framework, we would then compare concurrent activity in higher-level attentional control regions (e.g., functionally localized FEF; Tehovnik et al., 2000) and visual areas (e.g., V1) that is observed in the empirical and in the modeling study.

In general, NBLs can connect output of different types of neural nets to any kind of functionally localizable regions, ranging from sensory retinotopic (DeYoe et al., 1996), tonotopic (Formisano et al., 2003), and somatotopic (Blankenburg et al., 2003) areas, to higherlevel regions such as object-preferring higher visual areas (e.g., fusiform face area; Kanwisher et al., 1997) or language areas (Fernández et al., 2001). Likewise, all sorts of anatomically defined regions can be linked to model areas. If a localizer scan had been lacking, we could have, for example, projected our V1 activity to an anatomically defined V1 (Hinds et al., 2009).

Further, not only perceptual processes but also potential neural substrates of cognitive processes (e.g., Brown and Braver, 2005; O'Reilly, 2006; Tagamets and Horwitz, 1998) can be investigated using the CBS framework. The wide applicability of integrating simulated and real data in brain space is becoming increasingly recognized. Arbib et al. (1995) were the first to compare computational simulations (on saccade generation) to neuroimaging (positron emission tomography or PET) data. Subsequently, Tagamets and Horwitz (1998) simulated fMRI data on a visual short-term memory task by transforming spiking output from their large-scale neural model into fMRI activity by means of a hemodynamic response function. Furthermore, they downsampled the resulting time series according to the appropriate TR and mimicked features of the empirical study, such as trial repetition and corresponding intertrial intervals. The Tagamets and Horwitz model was extended to working memory processes in the auditory domain by Husain et al. (2004), and for the first time, a quantitative comparison between simulated and observed fMRI data was made. Other modeling efforts that simulate fMRI data in the field of working memory come from Deco et al. (2004) and from Chadderon and Sporns (2006) who implemented dopaminergic modulations in their neural network. Although working memory received a lot of attention, there have also been attempts to relate neuromodeling and fMRI data in the field of attention (Corchs and Deco, 2002) and conflict processing (Herd et al., 2006; Brown and Braver, 2005).

However, none of the previously mentioned integration approaches provided the direct topographic correspondence between computational units at the model and brain level that our CBS framework offers. This close correspondence greatly facilitates the direct spatial comparison between simulated and empirically obtained fMRI results, which may stimulate a tighter integration of computational and experimental neuroscience. In our modeling approach, spatial and temporal comparisons between various levels of resolution (as offered by different methods) can be made: First, our 
network modeling system is able to generate multiple output data types, ranging from integrative synaptic activity levels and mean spike activity to fMRI and electro- and magnetoencephalography (EEG/MEG) data types. In CBS, it is possible to switch between displaying the different output data types produced by the same running network simulation (see Fig. 6B). Second, these different modes of network output can be compared with different types of obtained data as the CBS modeling framework can be conveniently integrated with recently developed extensions of the BrainVoyager QX software package that permits signal projection for EEG/MEG data (Esposito et al., 2009), in addition to fMRI data. The possibility to compare different model output in terms of different methods may help to investigate unanswered fundamental question about the coupling between integrated synaptic activity and fMRI signal (Logothetis et al., 2001) or about the relationship between neuronal activity distributions and the spread of fMRI signal. Furthermore, this might also facilitate the reconciliation of apparently conflicting results from human fMRI studies and spike recording studies in animals that investigate the same phenomena across species (Maier et al., 2008). With the advent of high-field fMRI imaging $(\geq 7 \mathrm{~T})$, it becomes possible to image brain activity in response to perceptual and cognitive events at a high spatial resolution, which may enable investigators to monitor activity in separate layers, columns, and other anatomical and functional subcompartments of cortical areas in the human brain. The activity patterns predicted by advanced computational models that implement the details of cortical circuitry could therefore be projected onto a very detailed brain space, in which the empirical data are also collected.

Our and other recent approaches that aim to integrate simulated and empirically acquired data can contribute to advanced crossfertilized model development: incremental, direct integration of computational and neuroimaging work provides the best biological validation of a computational model and simultaneously helps to interpret experimental observations in a comprehensive brain model. We suggest that testing model predictions in a common brain space with observed brain data will become a particularly important tool in future cognitive neuroscience research.

\section{Acknowledgments}

We kindly acknowledge Joel Reithler for comments on previous versions of the manuscript. This project was financially supported by grants from the Netherlands Organization of Scientific Research (NWO) to V.V. (grant 451-07-014) and to P.D.W. (grants 453-04-002 and 400-04-036). Judith Peters and Bert Jans may both claim first authorship of this work.

\section{References}

Arbib, M.A., Bischoff, A., Fagg, A.H., Grafton, S.T., 1995. Synthetic PET: analyzing largescale properties of neural networks. Hum. Brain Mapp. 225-233.

Arrington, K.F., 1994. The temporal dynamics of brightness filling-in. Vis. Res. 34, 3371-3387.

Barkan, Y., Spitzer, H., Einav, S., 2008. Brightness contrast-contrast induction model predicts assimilation and inverted assimilation effects. J. Vis. 8 (7), 1-26.

Bartfeld, E., Grinvald, A., 1992. Relationships between orientation-preference pinwheels, cytochrome oxidase blobs, and ocular-dominance columns in primate striate cortex. Proc. Natl. Acad. Sci. U.S.A. 89, 11905-11909.

Blakeslee, B., McCourt, M.E., 1999. A multiscale spatial filtering account of the White effect, simultaneous brightness contrast and grating induction. Vis. Res. 39, 4361-4377.

Blakeslee, B., McCourt, M.E., 2001. A multiscale spatial filtering account of the Wertheimer-Benary effect and the corrugated Mondrian. Vis. Res. 41, 2487-2502.

Blakeslee, B., McCourt, M.E., 2004. A unified theory of brightness contrast and assimilation incorporating oriented multiscale spatial filtering and contrast normalization. Vis. Res. 44, 2483-2503.

Blakeslee, B., Pasieka, W., McCourt, M.E., 2005. Oriented multiscale spatial filtering and contrast normalization: a parsimonious model of brightness induction in a continuum of stimuli including White, Howe and simultaneous brightness contrast. Vis. Res. 45, 607-615.
Blankenburg, F., Ruben, J., Meyer, R., Schwiemann, J., Villringer, A., 2003. Evidence for a rostral-to-caudal somatotopic organization in human primary somatosensory cortex with mirror-reversal in areas $3 \mathrm{~b}$ and 1 . Cereb. Cortex 13, 987-993.

Blasdel, G.G., Lund, J.S., Fitzpatrick, D., 1985. Intrinsic connections of macaque striate cortex: axonal projections of cells outside lamina 4C. J. Neurosci. 5, 3350-3369.

Bonhoeffer, T., Kim, D.S., Malonek, D., Shoham, D., Grinvald, A., 1995. Optical imaging of the layout of functional domains in area 17 and across the area $17 / 18$ border in cat visual cortex. Eur. J. NeuroSci. 7, 1973-1988.

Boyaci, H., Fang, F., Murray, S.O., Kersten, D., 2007. Responses to brightness variations in early human visual cortex. Curr. Biol. 17, 989-993.

Brown, J.W., Braver, T.S., 2005. Learned predictions of error likelihood in the anterior cingulate cortex. Science 307, 1118-1121.

Burt, P.J., Adelson, E.H., 1983. The Laplacian pyramid as a compact image code. IEEE Trans. Commun. 31, 532-540.

Chadderdon, G.L., Sporns, O., 2006. A large-scale neurocomputational model of taskoriented behavior selection and working memory in the prefrontal cortex. J. Cogn. Neurosci. 18, 242-257.

Corbetta, M., Shulman, G.L., 2002. Control of goal-directed and stimulus-driven attention in the brain. Nat. Rev. Neurosci. 3, 201-215.

Corchs, S., Deco, G., 2002. Large-scale neural model for visual attention: integration of experimental single-cell and fMRI data. Cereb. Cortex 12, 339-348.

Cornelissen, F.W., Wade, A.R., Vladusich, T., Dougherty, R.F., Wandell, B.A., 2006. No functional magnetic resonance imaging evidence for brightness and color filling-in in early human visual cortex. J. Neurosci. 26, 3634-3641.

Cornsweet, 1970. Visual Perception. Academic Press, New York.

Dakin, S.C., Bex, P.J., 2003. Natural image statistics mediate brightness 'filling in'. Proc. Biol. Sci. 270, 2341-2348.

De Valois, R.L., Webster, M.A., De Valois, K.K., Lingelbach, B., 1986. Temporal properties of brightness and color induction. Vis. Res. 26, 887-897.

Deco, G., Rolls, E.T., Horwitz, B., 2004. "What" and "where" in visual working memory: a computational neurodynamical perspective for integrating FMRI and singleneuron data. J. Cogn. Neurosci. 16, 683-701.

Denett, D., 1991. Consciousness Explained. Little Brown, Boston.

DeYoe, E.A., Van Essen, D.C., 1988. Concurrent processing streams in monkey visual cortex. Trends Neurosci. 11, 219-226.

DeYoe, E.A., Carman, G.J., Bandettini, P., Glickman, S., Wieser, J., Cox, R., Miller, D., Neitz, J., 1996. Mapping striate and extrastriate visual areas in human cerebral cortex. Proc. Natl. Acad. Sci. U.S.A. 93, 2382-2386.

Esposito, F., Aragri, A., Piccoli, T., Tedeschi, G., Goebel, R., Di Salle, F., 2009. Distributed analysis of simultaneous EEG-fMRI time-series: modeling and interpretation issues. Magn. Reson. Imaging 27, 1120-1130.

Fernández, G., de Greiff, A., von Oertzen, J., Reuber, M., Lun, S., Klaver, P., Ruhlmann, J., Reul, J., Elger, C.E., 2001. Language mapping in less than 15 minutes: real-time functional MRI during routine clinical investigation. Neuroimage 14, 585-594.

Fitzpatrick, D., Lund, J.S., Blasdel, G.G., 1985. Intrinsic connections of macaque striate cortex: afferent and efferent connections of lamina 4C. J. Neurosci. 5, 3329-3349.

Formisano, E., Kim, D.S., Di Salle, F., van de Moortele, P.F., Ugurbil, K., Goebel, R., 2003. Mirror-symmetric tonotopic maps in human primary auditory cortex. Neuron 40 , 859-869.

Friedman, H.S., Zhou, H., von der Heydt, R., 2003. The coding of uniform colour figures in monkey visual cortex. J. Physiol. 548, 593-613.

Friston, K.J., Fletcher, P., Josephs, O., Holmes, A., Rugg, M.D., Turner, R., 1998. Eventrelated fMRI: characterizing differential responses. Neuroimage 7, 30-40.

Gerrits, H.J., Vendrik, A.J., 1970. Simultaneous contrast, filling-in process and information processing in man's visual system. Exp. Brain Res. 11, 411-430.

Gerrits, H.J., De Haan, B., Vendrik, A.J., 1966. Experiments with retinal stabilized images. Relations between the observations and neural data. Vis. Res. 6, 427-440.

Goebel, R., 1993. Perceiving complex visual scenes: an oscillator neural network model that integrates selective attention, perceptual organisation, and invariant recognition. In: Giles, C., Hanson, S., Cowan, J. (Eds.), Advances in Neural Information Processing Systems 5. Morgan Kaufmann, San Diego.

Goebel, R., De Weerd, P., 2009. Perceptual filling-in: from experimental data to neural network modeling. In: Gazzaniga, M. (Ed.), The Cognitive Neurosciences IV. MIT Press, Cambridge.

Grimson, W.E., 1982. A computational theory of visual surface interpolation. Philos. Trans. R. Soc. London 298, 395-427.

Grossberg, S., 1987a. Cortical dynamics of three-dimensional form, color, and brightness perception: I. Monocular theory. Percept. Psychophys. 41, 87-116.

Grossberg, S., 1987b. Cortical dynamics of three-dimensional form, color, and brightness perception: II. Binocular theory. Percept. Psychophys. 41, 117-158.

Grossberg, S., 2003. Filling-in the forms: Surface and boundary interaction in visual cortex. In: Pessoa, L., De Weerd, P. (Eds.), Filling-in: From Perceptual Completion to Skill Learning. University Press, Oxford, pp. 13-37.

Grossberg, S., Raizada, R., 2000. Contrast-sensitive perceptual grouping and object-based attention in the laminar circuits of primary visual cortex. Vis. Res. 40,1413-1432.

Grossberg, S., Todorovic, D., 1988. Neural dynamics of 1-D and 2-D brightness perception: a unified model of classical and recent phenomena. Percept. Psychophys. 43, 241-277.

Heitger, F., von der Heydt, R., Peterhans, E., Rosenthaler, L., Kübler, O., 1998. Simulation of neural contour mechanisms: representing anomalous contours. Image Vis. Comput. 16, 409-423.

Herd, S.A., Banich, M.T., O'Reilly, R.C., 2006. Neural mechanisms of cognitive control: an integrative model of Stroop task performance and FMRI data. J. Cogn. Neurosci. 18, $22-32$.

Hinds, O., Polimeni, J.R., Rajendran, N., Balasubramanian, M., Amunts, K., Zilles, K., Schwartz, E.L., Fischl, B., Triantafyllou, C., 2009. Locating the functional and anatomical boundaries of human primary visual cortex. Neuroimage 46, 915-922. 
Huang, X., Paradiso, M.A., 2008. V1 response timing and surface filling-in. J. Neurophysiol. 100, 539-547.

Hubel, D.H., Livingstone, M.S., 1987. Segregation of form, color, and stereopsis in primate area 18. J. Neurosci. 7, 3378-3415.

Hubel, D.H., Wiesel, T.N., 1959. Receptive fields of single neurones in the cat's striate cortex. J. Physiol. 148, 574-591.

Hubel, D.H., Wiesel, T.N., 1962. Receptive fields, binocular interaction and functional architecture in the cat's visual cortex. J. Physiol. 160, 106-154.

Hung, C.P., Ramsden, B.M., Chen, L.M., Roe, A.W., 2001. Building surfaces from borders in areas 17 and 18 of the cat. Vis. Res. 41, 1389-1407.

Hung, C.P., Ramsden, B.M., Roe, A.W., 2007. A functional circuitry for edge-induced brightness perception. Nat. Neurosci. 10, 1185-1190.

Husain, F.T., Tagamets, M.A., Fromm, S.J., Braun, A.R., Horwitz, B., 2004. Relating neuronal dynamics for auditory object processing to neuroimaging activity. NeuroImage 21, 1701-1720.

Jehee, J.F., Lamme, V.A., Roelfsema, P.R., 2007. Boundary assignment in a recurrent network architecture. Vis. Res. 47, 1153-1165.

Jones, J.P., Palmer, L.A., 1987. An evaluation of the two-dimensional Gabor filter model of simple receptive fields in cat striate cortex. J. Neurophysiol. 58, 1233-1258.

Kanwisher, N., McDermott,J., Chun, M.M., 1997. The fusiform face area: a module in human extrastriate cortex specialized for face perception. J. Neurosci. 17, 4302-4311.

Kay, K.N., Naselaris, T., Prenger, R.J., Gallant, J.L., 2008. Identifying natural images from human brain activity. Nature 452, 352-355.

Kayama, Y., Riso, R.R., Bartlett, J.R., Doty, R.W., 1979. Luxotonic responses of units in macaque striate cortex. J. Neurophysiol. 42, 1495-1517.

Kinoshita, M., Komatsu, H., 2001. Neural representation of the luminance and brightness of a uniform surface in the macaque primary visual cortex. J. Neurophysiol. 86, 2559-2570.

Komatsu, H., Kinoshita, M., Murakami, I., 2000. Neural Responses in the retinotopic representation of the blind spot in the macaque V1 to stimuli for perceptual fillingin. J. Neurosci. 20, 9310-9319.

Kriegeskorte, N., Goebel, R., 2001. An efficient algorithm for topologically correct segmentation of the cortical sheet in anatomical MR volumes. Neuroimage 14, 329-346.

Landisman, C.E., Ts'o, D.Y., 2002. Color processing in macaque striate cortex: relationships to ocular dominance, cytochrome oxidase, and orientation. J. Neurophysiol. 87, 3126-3137.

Logothetis, N.K., Pauls, J., Augath, M., Trinath, T., Oeltermann, A., 2001. Neurophysiological investigation of the basis of the fMRI signal. Nature 412, 150-157.

Lu, H.D., Roe, A.W., 2008. Functional organization of color domains in V1 and V2 of macaque monkey revealed by optical imaging. Cereb. Cortex 18, 516-533.

Maguire, W.M., Baizer, J.S., 1982. Luminance coding of briefly presented stimuli in area 17 of the rhesus monkey. J. Neurophysiol. 47, 128-137.

Maier, A., Wilke, M., Aura, C., Zhu, C., Ye, F.Q., Leopold, D.A., 2008. Divergence of fMRI and neural signals in V1 during perceptual suppression in the awake monkey. Nat. Neurosci. 11, 1193-1200.

McCourt, M.E., 1982. A spatial frequency dependent grating-induction effect. Vis. Res. $22,119-134$.

Mendola, J.D., Conner, I.P., Sharma, S., Bahekar, A., Lemieux, S., 2006. fMRI measures of perceptual filling-in in the human visual cortex. J. Cogn. Neurosci. 18, 363-375.

Murakami, I., Komatsu, H., Kinoshita, M., 1997. Perceptual filling-in at the scotoma following a monocular retinal lesion in the monkey. Vis. Neurosci. 14, 89-101.

Neumann, H., Pessoa, L., Hansen, T., 2001. Visual filling-in for computing perceptual surface properties. Vis. Neurosci. 85, 355-369.

O'Reilly, R.C., 2006. Biologically based computational models of high-level cognition. Science 314, 91-94.

Otazu, X., Vanrell, M., Párraga, C., 2008. Multiresolution wavelet framework models brightness induction effects. Vis. Res. 48, 733-751.
Paradiso, M.A., Nakayama, K., 1991. Brightness perception and filling-in. Vis. Res. 31 1221-1236.

Pereverzeva, M., Murray, S.O., 2008. Neural activity in human V1 correlates with dynamic lightness induction. J. Vis. 8, 1-10.

Perna, A., Tosetti, M., Montanaro, D., Morrone, M.C., 2005. Neuronal mechanisms for illusory brightness perception in humans. Neuron 47, 645-651.

Pessoa, L., De Weerd, P. (Eds.), 2003. Filling-in: From Perceptual Completion to Skil Learning. Oxford University Press, Oxford.

Purves, D., Shimpi, A., Lotto, R.B., 1999. An empirical explanation of the Cornsweet effect. J. Neurosci. 19, 8542-8551.

Raizada, R., Grossberg, S., 2001. Context-sensitive bindings by the laminar circuits of V1 and V2: a unified model of perceptual grouping, attention, and orientation contrast. Vis. Cogn. 8, 431-466.

Rodieck, R.W., 1965. Quantitative analysis of cat retinal ganglion cell response to visual stimuli. Vis. Res. 5, 583-601.

Roe, A.W., Lu, H.D., Hung, C.P., 2005. Cortical processing of a brightness illusion. Proc Natl. Acad. Sci. U.S.A. 102, 3869-3874.

Roebroeck, A., Formisano, E., Goebel, R., 2005. Mapping directed influence over the brain using Granger causality and fMRI. Neuroimage 25, 230-242.

Roelfsema, P.R., Lamme, V.A., Spekreijse, H., Bosch, H., 2002. Figure-ground segregation in a recurrent network architecture. J. Cogn. Neurosci. 14, 525-537.

Rossi, A.F., Paradiso, M.A., 1999. Neural correlates of perceived brightness in the retina, lateral geniculate nucleus, and striate cortex. J. Neurosci. 19, 6145-6156.

Rossi, A.F., Rittenhouse, C.D., Paradiso, M.A., 1996. The representation of brightness in primary visual cortex. Science 273, 1104-1107.

Sasaki, Y., Watanabe, T., 2004. The primary visual cortex fills in color. Proc. Natl. Acad. Sci. U.S.A. 101, 18251-18256.

Sereno, M.I., Dale, A.M., Reppas, J.B., Kwong, K.K., Belliveau, J.W., Brady, T.J., Rosen, B.R., Tootell, R.B., 1995. Borders of multiple visual areas in humans revealed by functional magnetic resonance imaging. Science 268, 889-893.

Shoham, D., Hubener, M., Schulze, S., Grinvald, A., Bonhoeffer, T., 1997. Spatio-temporal frequency domains and their relation to cytochrome oxidase staining in cat visual cortex. Nature 385, 529-533.

Stromeyer III, C.F., Kronauer, R.E., Madsen, J.C., 1984. Adaptive processes controlling sensitivity of short-wave cone pathways to different spatial frequencies. Vis. Res. 24, 827-834.

Tagamets, M.A., Horwitz, B., 1998. Integrating electrophysiological and anatomical experimental data to create a large-scale model that simulates a delayed match-tosample human brain imaging study. Cereb. Cortex 8, 310-320.

Tehovnik, E.J., Sommer, M.A., Chou, I.H., Slocum, W.M., Schiller, P.H., 2000. Eye fields in the frontal lobes of primates. Brain Res. Brain Res. Rev. 32, 413-448.

Troxler, D., 1804. Ueber das Verschwindern gegebener Gegenstande innerhalb unsers Gesichtskreises. In: Schmidt, J. (Ed.), Ophtalmologisches Bibliothek. Springer, Jena, pp. 431-573.

Ts'o, D.Y., Roe, A.W., Gilbert, C.D., 2001. A hierarchy of the functional organization for color, form and disparity in primate visual area V2. Vis. Res. 41, 1333-1349.

Wachtler, T., Sejnowski, T.J., Albright, T.D., 2003. Representation of color stimuli in awake macaque primary visual cortex. Neuron 37, 681-691.

Wang, Y., Xiao, Y., Felleman, D.J., 2007. V2 thin stripes contain spatially organized representations of achromatic luminance change. Cereb. Cortex 17, 116-129.

White, M., 1979. A new effect of pattern on perceived lightness. Perception 8 413-416.

Yabuta, N.H., Callaway, E.M., 1998. Cytochrome-oxidase blobs and intrinsic horizontal connections of layer $2 / 3$ pyramidal neurons in primate V1. Vis. Neurosci. 15, 1007-1027.

Yacoub, E., Harel, N., Ugurbil, K., 2008. High-field fMRI unveils orientation columns in humans. Proc. Natl. Acad. Sci. U.S.A. 105, 10607-10612. 